\title{
Input-Output Features of Anatomically Identified CA3 Neurons during Hippocampal Sharp Wave/Ripple Oscillation In Vitro
}

\author{
Norbert Hájos, ${ }^{1 \star}$ Mária R. Karlócai, ${ }^{1 \star}$ Beáta Németh, ${ }^{1}$ István Ulbert, ${ }^{2,3}$ Hannah Monyer, ${ }^{4}$ Gábor Szabó, ${ }^{1}$ Ferenc Erdélyii, ${ }^{1}$ \\ Tamás F. Freund, ${ }^{1,2}$ and Attila I. Gulyás ${ }^{1}$ \\ ${ }^{1}$ Institute of Experimental Medicine, Hungarian Academy of Sciences, H-1083 Budapest, Hungary, ${ }^{2}$ éter Pázmány Catholic University, Faculty of \\ Information Technology, H-1088, Budapest, Hungary, ${ }^{3}$ Institute of Cognitive Neuroscience and Psychology, Research Centre for Natural Sciences, \\ Hungarian Academy of Sciences, H-1025, Budapest, Hungary, and ${ }^{4}$ Department of Clinical Neurobiology, University Hospital of Neurology, 69120 \\ Heidelberg, Germany
}

Hippocampal sharp waves and the associated ripple oscillations (SWRs) are implicated in memory processes. These network events emerge intrinsically in the CA3 network. To understand cellular interactions that generate SWRs, we detected first spiking activity followed by recording of synaptic currents in distinct types of anatomically identified CA3 neurons during SWRs that occurred spontaneously in mouse hippocampal slices. We observed that the vast majority of interneurons fired during SWRs, whereas only a small portion of pyramidal cells was found to spike. There were substantial differences in the firing behavior among interneuron groups; parvalbumin-expressing basket cells were one of the most active GABAergic cells during SWRs, whereas ivy cells were silent. Analysis of the synaptic currents during SWRs uncovered that the dominant synaptic input to the pyramidal cell was inhibitory, whereas spiking interneurons received larger synaptic excitation than inhibition. The discharge of all interneurons was primarily determined by the magnitude and the timing of synaptic excitation. Strikingly, we observed that the temporal structure of synaptic excitation and inhibition during SWRs significantly differed between parvalbumin-containing basket cells, axoaxonic cells, and type 1 cannabinoid receptor (CB1)-expressing basket cells, which might explain their distinct recruitment to these synchronous events. Our data support the hypothesis that the active current sources restricted to the stratum pyramidale during SWRs originate from the synaptic output of parvalbuminexpressing basket cells. Thus, in addition to gamma oscillation, these GABAergic cells play a central role in SWR generation.

\section{Introduction}

Sharp wave-associated ripple oscillations (SWRs), which reflect fast synchronous network activity at 150-200 Hz, decorate the hippocampal electroencephalogram recorded during both awake immobility and sleep (Buzsáki, 1986). These events have been suggested to be associated with memory consolidation (Buzsáki, 1989). In support of this suggestion, recent studies showed that selective disruption of SWRs during post-training consolidation periods impairs hippocampus-dependent memory (Girardeau et al., 2009; Jadhav et al., 2012). SWRs are thought to reflect the flow

Received Dec. 14, 2012; revised June 3, 2013; accepted June 4, 2013

Author contributions: N.H., T.F.F., and A.I.G. designed research; N.H., M.R.K., and B.N. performed research; I.U., H.M., G.S., and F.E. contributed unpublished reagents/analytic tools; N.H., M.R.K., I.U., and A.I.G. analyzed data; N.H., T.F.F., and A.I.G. wrote the paper.

This work was supported by the Wellcome Trust International Senior Research Fellowship, the National Office for Research and Technology (OMFB-01678/2009), the Hungarian Scientific Research Fund (NNF 78917, NNF 85659, OTKA K83251, 0TKA K81354), French-Hungarian Grants ANR-TÉT Neurogen, ANR-TÉT Multisca, and TÁMOP-4.2.1.B11/2/KMR-2011-0002. We thank Dr Szabolcs Káli for his comments, Erzsébet Gregori for her excellent technical assistance and Dr. Gergely Szabó for providing some data.

${ }^{*}$ N.H. and M.R.K. contributed equally to this study.

Correspondence should be addressed to Norbert Hájos, Institute of Experimental Medicine, Hungarian Academy of Sciences, Budapest, H-1450, Hungary. E-mail: hajos@koki.hu.

DOI:10.1523/JNEUROSCI.5729-12.2013

Copyright $\odot 2013$ the authors $\quad 0270-6474 / 13 / 3311677-15 \$ 15.00 / 0$ of information from area CA3 to CA1 within the hippocampus as well as between the hippocampus and its output structures, where they significantly modulate the spiking activity of local neurons (Chrobak and Buzsáki, 1996; Dragoi et al., 1999; Logothesis et al., 2012). Despite extensive investigations of SWRs in vivo, the network mechanisms underlying the generation of these population events remain largely unknown.

Though SWRs can be recorded from both CA3 and CA1, it has been shown that they are generated in CA3 and are only transmitted to CA1 (Csicsvari et al., 2000; Nakashiba et al., 2009). There is no "wave-by-wave" transfer of ripples from the CA3 region to CA1, only the SWR envelop is coincident (Sullivan et al., 2011). In vivo data showed that on average the activity of both pyramidal cells and interneurons increases during SWRs, and it is hypothesized that both neuron types are necessary for the generation of this population activity (Csicsvari et al., 2000). To date, however, the activity of only a limited number of anatomically identified hippocampal interneurons has been correlated with SWRs (Klausberger and Somogyi, 2008). Importantly, these recordings were almost exclusively done in CA1 that does not generate SWRs independently, but inherits these population events from CA3.

To clarify the synaptic mechanisms underlying the SWR generation, in vitro models of these population events have been 
introduced (Kubota et al., 2003; Maier et al., 2003; Behrens et al., 2005; Wu et al., 2005; de la Prida et al., 2006). This network activity has been shown to emerge spontaneously in mouse hippocampal slices, or could be induced by increasing the excitability of neurons in rat slices. As in the intact brain, SWRs recorded in hippocampal slices were found to be initiated by neuronal ensembles in CA3, and then propagate to CA1. Moreover, it was shown in vitro that both excitatory and inhibitory synaptic transmission was necessary for the generation of SWRs, and only a small proportion of pyramidal cells was active during these network events similar to what was found in vivo (Csicsvari et al., 2000; Le Van Quyen et al., 2008).

To reveal the mechanism of SWR generation, we aimed to uncover the firing properties of different types of anatomically identified neurons in CA3 during spontaneously occurring SWRs in mouse hippocampal slices. By relating the synaptic currents to the spiking of individual neurons we found that the distinct synaptic input in different neurons during SWRs could at least partially explain their different spiking behavior. In addition, our results propose a central role for parvalbumin-containing basket cells in SWR generation.

\section{Materials and Methods}

Animals were kept and used according to the regulations of the European Community's Council Directive of 24 November, 1986 (86/609/EEC), and experimental procedures were reviewed and approved by the Animal Welfare Committee of the Institute of Experimental Medicine, Hungarian Academy of Sciences, Budapest.

CD1 mice of both sexes (postnatal day 17-29) were used in most of the experiments unless it is specified. To measure selectively from cells containing the $\mathrm{Ca}^{2+}$ binding protein parvalbumin (PV), transgenic mice expressing the enhanced green fluorescent protein (eGFP) controlled by PV promoter (Meyer et al., 2002) were used in this study (postnatal day 18-25). Cholecystokinin/CB1 cannabinoid receptor expressing interneurons were sampled in slices prepared from GAD65-EGFP transgenic mice (postnatal day 19-23) (Lopez-Bendito et al., 2004). In all cases, the mice were decapitated under deep isoflurane anesthesia. The brain was removed into ice-cold cutting solution, which had been bubbled with $95 \% \mathrm{O}_{2}-5 \% \mathrm{CO}_{2}$ (carbogen gas) for at least $30 \mathrm{~min}$ before use. The cutting solution contained the following (in $\mathrm{mM}$ ): 205 sucrose, 2.5 $\mathrm{KCl}, 26 \mathrm{NaHCO}_{3}, 0.5 \mathrm{CaCl}_{2}, 5 \mathrm{MgCl}_{2}, 1.25 \mathrm{NaH}_{2} \mathrm{PO}_{4}, 10$ glucose, saturated with $95 \% \mathrm{O}_{2}-5 \% \mathrm{CO}_{2}$ ). Horizontal hippocampal slices of $400-500$ $\mu \mathrm{m}$ thickness were cut using a vibratome (Leica VT1000S or VT1200S).

After acute slice preparation the slices were placed into an interfacetype holding chamber for recovery. This chamber contained standard aCSF at $35^{\circ} \mathrm{C}$ that gradually cooled down to room temperature. The aCSF had the following composition (in mM): $126 \mathrm{NaCl}, 2.5 \mathrm{KCl}, 26 \mathrm{NaHCO}_{3}$, $2 \mathrm{CaCl}_{2}, 2 \mathrm{MgCl}_{2}, 1.25 \mathrm{NaH}_{2} \mathrm{PO}_{4}, 10$ glucose, saturated with $95 \% \mathrm{O}_{2}-5 \%$ $\mathrm{CO}_{2}$. After incubation for at least $1 \mathrm{~h}$ slices were transferred individually into a submerged-style recording chamber equipped with a dual superfusion system for improved metabolic supply to the slices (Hájos et al., 2009). In this design, the slices were placed on a metal mesh and two separate fluid inlets allowed aCSF to flow both above and below the slices with a rate of $3-3.5 \mathrm{ml} / \mathrm{min}$ for each flow channel at $30-32^{\circ} \mathrm{C}$ (Supertech Instruments; www.super-tech.eu).

Standard patch electrodes were used in all recording configurations (i.e., in whole-cell patch-clamp, loose-patch, and field potential recordings). Pipette resistances were 3-6 M $\Omega$ when filled either with the intrapipette solution or with aCSF. The intrapipette solution contained the following (in $\mathrm{mm}$ ): $138 \mathrm{~K}$-gluconate, $3 \mathrm{CsCl}, 10$ disodium creatine phosphate, 4 Mg-ATP, 0.4 Tris-GTP, 10 HEPES, 0.2 QX 314, pH 7.38, 285 $\mathrm{mOsm} \cdot 1^{-1}$. For later morphological identification of the recorded cells biocytin in a concentration of $3-5 \mathrm{mg} / \mathrm{ml}$ was added to the pipette solution freshly before use.

Extracellular recordings and current source density calculation. The local field potential (LFP) was recorded with a laminar multielectrode array ( 24 channels, $50 \mu \mathrm{m}$ intercontact distance, Neuronelektród; http://www. neuronelektrod.hu/) using a custom made referential amplifier system (bandpass from $0.1 \mathrm{~Hz}$ to $7 \mathrm{kHz}$; Ulbert et al., 2001). Signals were digitized with a 16 bit resolution analog-to-digital converter (National Instruments) and recorded at $20 \mathrm{kHz}$ sampling rate on each channel, using a custom made virtual instrument in LabView (National Instruments). The laminar multielectrode array was placed on the surface of the hippocampal slice perpendicularly to the pyramidal cell layer. In this way the entire region was covered by the array so that extracellular recordings were made from each hippocampal layer. Current source density (CSD) calculations were made using the three-point formula smoothed by Hamming window (Ulbert et al., 2001). Results are depicted on a heat map using custom made software.

Data acquisition. All other data were recorded with a Multiclamp 700B amplifier (Molecular Devices). As a first step, two pipettes filled with aCSF were used. LFPs were monitored with a pipette placed into the stratum pyramidale of the CA3 area, while another pipette was used to concomitantly record the firing activity of individual neurons in the CA3 region. The loose-patch recordings of the neuronal discharges were visually guided using differential interference contrast microscopy (Olympus BX61W) for 2-5 min, depending on the firing frequency of the cell. This pipette was then withdrawn from the slice, and whole-cell patchclamp recordings were performed on the same cells with another pipette filled with intrapipette solution. Access resistance was in the range of 5-20 M $\Omega$. Only recordings, where the access resistance did not change substantially $(>25 \%)$, were included in the study. Reported values of voltage measurements were not corrected for the junction potential. To record EPSCs and IPSCs, cells were voltage clamped at a holding potential of the estimated reversal potential for IPSCs $(\sim-80 \mathrm{mV})$ and EPSCs $(\sim 0 \mathrm{mV})$, respectively. Both field and unit recordings were low-pass filtered at $3 \mathrm{kHz}$ using the built-in Bessel filter of the amplifier. Data were digitized at $10 \mathrm{kHz}$ with a PCI-6042E board (National instruments) using EVAN 1.3 software (courtesy of Prof. Istvan Mody, UCLA, CA), and were analyzed offline with custom-made programs written in MATLAB 7.0.4 and Delphi (by A.I.G).

Digital signal processing and analysis. Signals were filtered with a twoway RC filter to preserve phase. All automatic detection steps were supervised. Spike detection in loose-patch recordings was done on $500 \mathrm{~Hz}$ high-pass-filtered traces using a threshold value of six times the SD of the signal. SWRs were predetected on $30 \mathrm{~Hz}$ low-pass-filtered field recordings using a threshold value of four times the SD of the signal. The predetected SWRs were then redetected using a program that measured various SWR features and eliminated recording artifacts similar to SWRs. Namely, on the low-pass-filtered signal the program measured: (1) peak amplitude and peak time of SWRs, (2) duration of the SWR positive phase crossing 3 times SD, (3) amplitude, time, and half decay of the negativity following the SWRs. On a ripple bandpass-filtered trace (170$200 \mathrm{~Hz}$ ) the program also detected (4) the time of ripple negative peaks and taking the absolute value of the ripple band-passed signal and lowpass filtering it calculated, and (5) the ripple power peak, time, and area. The same program calculated the number of spikes of the recorded neuron during each SWR, and assigned to each spike a time relative to SWR peak and a phase relative to ripple negativities. The algorithm did not assign a phase to a spike when it was not between two subsequent ripple negativities. Circular statistics were then used to calculate average ripple phase and the strength of the coupling. Ripple frequency was calculated by Fast Fourier transformation or by calculating the characteristic ripple negativity interevent interval, both measurement put the ripple frequency $\sim 184 \mathrm{~Hz}$ (see Results, below).

Synaptic currents during SWRs were calculated in flexible windows set by the width of the actual SWR. Synaptic conductances were calculated by dividing the current values with the difference of the holding potential and the experimentally determined reversal potential for the measured current for each cell using the following:

$$
g_{e / i}=\frac{I_{e / i}}{\left(V_{h}-E_{e / i}^{r e v}\right)},
$$

where $I_{e / i}$ is the phasic excitatory/inhibitory current, $V_{h}$ is the holding potential, and $E_{e / i}^{r e v}$ is the reversal potential for the conductance of interest. 
Table 1. Spiking properties of distinct types of anatomically-identified neurons during SWRs

\begin{tabular}{lcccccccc}
\hline & PC & PV + BC & AAC & CB1 + BC & OLM & 00 & OR & RAD \\
\cline { 2 - 8 } & All cells & & & & & & \\
\cline { 2 - 8 } & $n=10$ & $n=9$ & $n=10$ & $n=7$ & $n=5$ & $n=4$ & $n=16$ & $n=4$ \\
\hline Firing Rate between SWRs (Hz) & $0.03 \pm 0.01$ & $3.24 \pm 1.88$ & $2.91 \pm 1.12$ & $0.66 \pm 0.41$ & $2.47 \pm 1.17$ & $0.21 \pm 0.09$ & $4.59 \pm 1.01$ & $15.42 \pm 10.61$ \\
Firing Rate during SWRs (Hz) & $0.49 \pm 0.11$ & $81.52 \pm 16.89$ & $45.11 \pm 11.17$ & $14.98 \pm 5.29$ & $38.87 \pm 12.24$ & $35.93 \pm 13.26$ & $40.34 \pm 7.21$ & $30.32 \pm 15.98$ \\
Spike no. during all SWRs & $0.07 \pm 0.01$ & $1.8 \pm 0.24$ & $0.89 \pm 0.21$ & $0.39 \pm 0.17$ & $1.0 \pm 0.08$ & $1.23 \pm 0.41$ & $0.83 \pm 0.13$ & $0.91 \pm 0.34$ \\
Ratio of SWRs with spikes & $0.062 \pm 0.016$ & $0.913 \pm 0.038$ & $0.592 \pm 0.117$ & $0.378 \pm 0.159$ & $0.881 \pm 0.047$ & $0.713 \pm 0.179$ & $0.649 \pm 0.071$ & $0.667 \pm 0.167$ \\
Spike no. during SWRs with spikes & $1.03 \pm 0.02$ & $1.91 \pm 0.21$ & $1.35 \pm 0.09$ & $1.02 \pm 0.02$ & $1.13 \pm 0.06$ & $1.57 \pm 0.24$ & $1.19 \pm 0.07$ & $1.25 \pm 0.2$ \\
Asymmetry index of spike distribution histograms & $0.07 \pm 0.01$ & $1.52 \pm 0.4$ & $6.47 \pm 1.88$ & $3.08 \pm 1.17$ & $1.52 \pm 0.13$ & $2.58 \pm 1.09$ & $3.73 \pm 0.64$ & $5.56 \pm 4.06$
\end{tabular}

Cells with phase-coupled firing

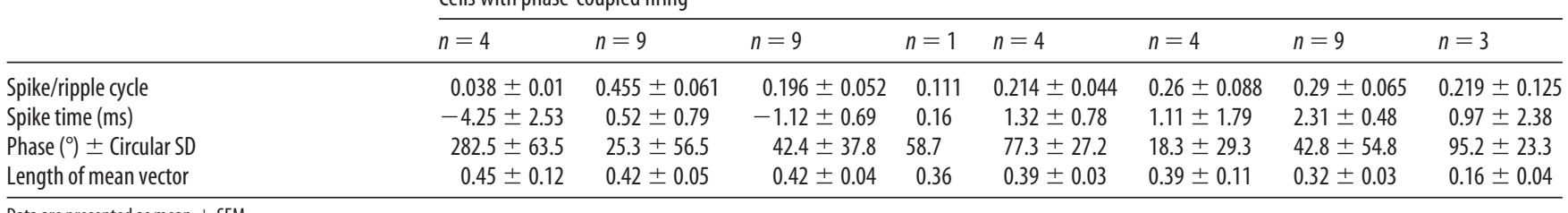

Data are presented as mean \pm SEM.

The conductances were used to estimate the net apparent reversal potential $\left(E_{s y n}^{r e v}\right)$ by solving as follows:

$$
\begin{aligned}
I_{s y n}=g_{e}\left(E_{s y n}^{r e v}-E_{e}^{r e v}\right)+g_{i}\left(E_{s y n}^{r e v}-E_{i}^{r e v}\right)= & \\
\Rightarrow E_{s y n}^{r e v} & =\frac{g_{e} E_{e}^{r e v}+g_{i} E_{i}^{r e v}}{g_{e}+g_{i}} .
\end{aligned}
$$

To calculate averages we identified the ripple cycle closest to the SWR peak and used its negative peak as triggering event for correlations.

Anatomical identification of the neurons. The recorded cells were filled with biocytin during the recordings. After the recording the slices were fixed in $4 \%$ paraformaldehyde in $0.1 \mathrm{~m}$ phosphate buffer (PB; $\mathrm{pH} 7.4$ ) for at least $1 \mathrm{~h}$, followed by washout with PB several times and incubation in $30 \%$ sucrose in $0.1 \mathrm{M} \mathrm{PB}$ for at least $2 \mathrm{~h}$. Then slices were freeze-thawed three times above liquid nitrogen and treated with $1 \% \mathrm{H}_{2} \mathrm{O}_{2}$ in PB for $15 \mathrm{~min}$ to reduce the endogenous peroxidase activity. Recorded cells were visualized using avidin-biotinylated horseradish peroxidase complex reaction (Vector Laboratories) with nickel-intensified 3,3'-diaminobenzidine as chromogen giving a dark reaction product. After dehydration and embedding in Durcupan cells were morphologically identified on the basis of their dendritic and axonal arborization. Representative neurons were reconstructed using a drawing tube.

Separation of basket and axoaxonic cells. To distinguish basket cells and axoaxonic cells, slices were resliced to $40-\mu \mathrm{m}$-thick sections and processed for immunofluorescence double labeling. Ankyrin G-immunostaining was applied together with biocytin visualization as described before (Gulyas et al., 2010). In our earlier studies, we validated this light microscopic identification of axoaxonic and basket cells by electron microscopy (Gulyás et al., 2010). Briefly, sections were treated with $0.2 \mathrm{mg} / \mathrm{ml}$ pepsin (Dako) in $0.2 \mathrm{M}$ $\mathrm{HCl}$ at $37^{\circ} \mathrm{C}$ for $15 \mathrm{~min}$ and were washed in $0.1 \mathrm{M} \mathrm{PB}$. Nonspecific binding sites were blocked in 10\% normal goat serum (Vector Laboratories) in TBS, $\mathrm{pH}$ 7.4, followed by incubation with a mouse anti-ankyrin G antibody (1: 100, Santa Cruz Biotechnology) diluted in TBS containing 2\% NGS and $0.05 \%$ Triton X-100 for $72 \mathrm{~h}$ at $4^{\circ} \mathrm{C}$. Following several washes in TBS, Alexa594-conjugated goat anti-mouse (1:200; Life Technologies) was used to visualize the ankyrin G-immunostaining, and Alexa488-conjugated streptavidin (1:500; Life Technologies) was used to label biocytin. Sections were then mounted on slides in Vectashield (Vector Laboratories). The staining was analyzed and images were taken by using an AxioImager.Z1 microscope (Zeiss). Subsequently, representative basket and axoaxonic cells were further developed by immunoperoxidase reaction using DAB-Ni for anatomical reconstruction.

Statistical comparisons. As the first step, we compared the data obtained in pyramidal cells with those recorded in all interneurons. Next, we compared data in the two groups of functionally distinct interneuron types, the perisomatic region-targeting interneurons (including parvalbumin-containing basket cells, axoaxonic cells and CB1-expressing basket cells) and dendritic layer-innervating interneurons [including oriens-lacunosum-moleculare (OLM) cells, oriens-oriens cells, oriens-radiatum cells, and radiatum cells]. Finally, we evaluated the statistical difference among cell types within the perisomatic region targeting-interneurons or within the group of dendritic layer-innervating interneurons. If the results were taken from a group with normal distribution based on a normality test, $t$ test, and ANOVA followed by Fisher post hoc test were used for comparison of two groups and multiple groups, respectively. If the normality test rejected the hypothesis that the results were taken from a group with normal distribution, Mann-Whitney $(\mathrm{M}-\mathrm{W})$ test and Kruskal-Wallis (K-W) ANOVA were used for comparison of two groups and multiple groups, respectively. To correlate normally distributed linear-linear variables the Pearson's correlation coefficient was used, and the results are equated as R. Statistica version 11 (Stat Soft) and OriginPro 8.6 (Origin Lab) was used, data are presented as mean \pm SEM, unless stated otherwise.

The Rayleigh probability $\left(p_{r}\right)$ was used to determine the significance of the phase-coupling. It was calculated by the following equation:

$$
p_{r}=e^{-z}\left(1+\frac{2 Z-Z^{2}}{4 n}-\frac{24 Z-132 Z^{2}+76 Z^{3}-9 Z^{4}}{288 n^{2}}\right),
$$

where $n$ is the number of spikes, and $Z=n r^{2}$ (Fisher, 1993). Events were considered to be phase-coupled, if the Rayleigh test indicated that they were not distributed randomly around the ripple cycle $\left(p_{r}<0.05\right.$; Zar, 1999). The circular SD reported in Table 1 was taken as follows:

$$
\sigma=\sqrt{-2 \text { in } r}
$$

where $r$ is the phase-coupling strength (Zar, 1999).

To test equality of means of angular variables the multisample Watson-Williams test was used. Circular statistics were performed using Oriana 2.0 software (Kovach Computing Services).

\section{Results}

In the CA3 region of mouse hippocampal slices, synchronous network events closely resembling SWRs recorded in vivo can be detected (Csicsvari et al., 2000; Maier et al., 2003). These synchronous activities occurred spontaneously at a rate of $1.1 \pm 0.08 \mathrm{~Hz}$ ( $n=92$ slices), and the frequency of the accompanying ripple oscillations was $185.8 \pm 1.3 \mathrm{~Hz}(n=92$; Fig. $1 A-C)$. Current source density analysis of SWRs showed a characteristic laminar profile with a dominant source in the stratum pyramidale and a dominant sink in the proximal part of the stratum radiatum bor- 
A

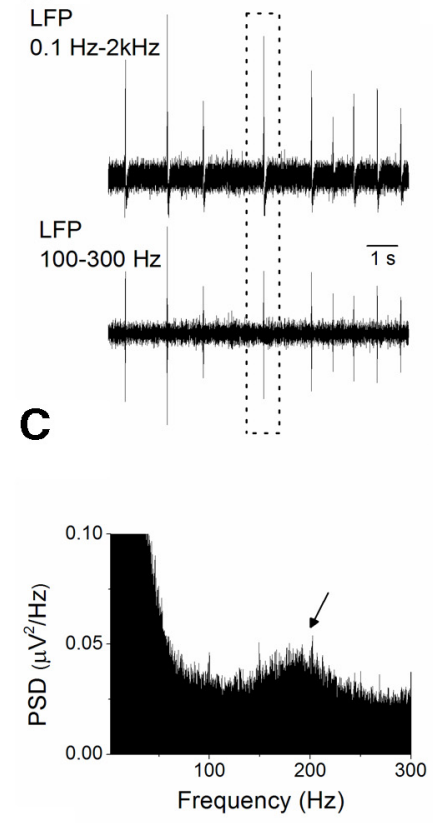

E

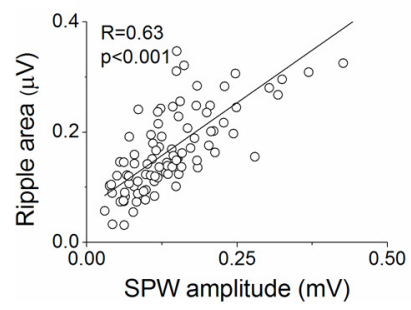

B

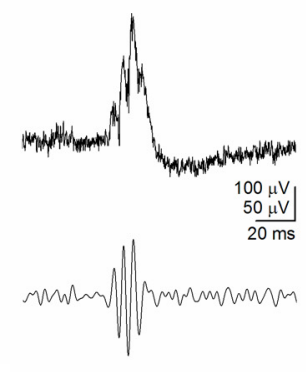

D

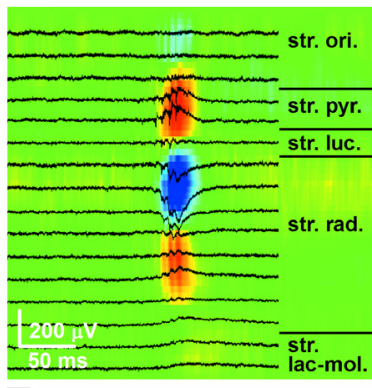

F

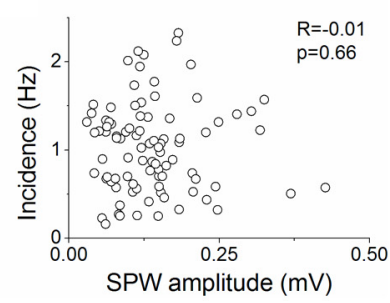

Figure 1. SWRs in hippocampal slices. $\boldsymbol{A}$, In LFP recorded from the stratum pyramidale of the CA3 region, spontaneously occurring SWRs could be observed. Ripple bandpass filtered version of the same trace is shown below. B, Magnification of boxed SWR in A. C, Power spectral density function of the trace in $\boldsymbol{A}$ showing ripple frequency peak (arrow). $\boldsymbol{D}$, LFP recorded with a laminar multielectrode array was used for calculating the current source density plot (below). A large sink (blue) and source (red) pair is present in the strata radiatum and pyramidale, respectively. The figure shows an individual LFP signal and a CSD obtained from this example signal. $\boldsymbol{E}$, Correlation between the sharp wave (SPW) amplitude and ripple area. $\boldsymbol{F}$, The rate of SWRs was independent of sharp wave amplitude. Each point on these plots is an averaged value from individual experiments $(n=79)$.

dered by a weaker source in the distal part of the stratum radiatum (Fig. 1D), comparable to that observed in intact animals or in other models of SWRs (Ellender et al., 2010; Sullivan et al., 2011). To characterize these events in more details, we measured the peak amplitude $(144.3 \pm 9.5 \mu \mathrm{V} ; n=92)$ and the half-width of sharp waves $(17.8 \pm 0.45 \mathrm{~ms} ; n=92)$, as well as the number of ripple cycles/event $(4.2 \pm 0.2 ; n=92)$ and the area of ripple oscillations $(0.17 \pm 0.01 \mu \mathrm{V} ; n=92)$ of those events that were recorded within the stratum pyramidale. When we compared the sharp wave amplitude with the area of ripple oscillations recorded in different slices, we found a significant correlation (Fig. $1 E$ ), indicating that these two events may share a common origin and/or generating mechanisms. In contrast, there was no relationship between the sharp wave amplitude and their incidence compared among slices (Fig. $1 F$ ).

\section{Recorded neuron types in CA3}

To uncover the spiking behavior and the synaptic input of distinct neuron types in CA3 during SWRs, we concomitantly recorded LFPs together with action potentials in loose-patch mode and subsequently postsynaptic currents in whole-cell mode. The intracellularly labeled neurons were then anatomically identified. Based on the dendritic and axonal arborization, recorded neurons were grouped post hoc into nine anatomical types (Freund and Buzsáki, 1996; Somogyi and Klausberger, 2005) and their input-output properties in relation to the SWRs were compared. Pyramidal cells had spiny dendrites spanning all layers and their rarely branching axons were found mainly in the stratum oriens and partially in the stratum radiatum ( $\mathrm{PC}, n=16$; Fig. $2 A)$. Three interneuron types having axons prevalently in pyramidal cell layer were distinguished. In PV-EGFP mice, we sampled both basket cells (PV + BC, $n=9$ ) and axoaxonic cells (AACs; $n=10$ ). Their dendrites found in all layers were either smooth or occasionally decorated with some spines. Axon arbor of both cell types was predominantly present in the stratum pyramidale (Fig. $2 A)$. Another type of basket cells expressing cholecystokinin and $\mathrm{CB} 1$ cannabinoid receptors was recorded in slices prepared from GAD65-EGFP mice (CB1 + BC, $n=13$ ). The majority of these interneurons had radial dendrites spanning all layers $(n=11)$, whereas the dendritic tree of two basket cells was mostly restricted to the stratum oriens. The axon of all basket cells ramified mainly in the stratum pyramidale, but some axon collaterals could be observed both in the strata lucidum and oriens (Fig. 2A).

Five interneuron types were separated with axons projecting to the dendritic layers; three of them had horizontal dendrites in the stratum oriens, whereas the dendritic tree of the remaining two cell types had spherical appearance. Dendrites of OLM cells bearing elongated filopodia-like spines were exclusively found in the stratum oriens, whereas their axons were present both in the strata oriens and lacunosum-moleculare. These interneurons were sampled either in slices prepared from the PV-EGFP mice $(n=2)$, or from wild-type mice ( $n=3$; OLM, $n=5$; Fig. $2 A)$. We also distinguished oriens-oriens cells, their smooth dendrites and often ramifying axons were restricted to the stratum oriens (OO, $n=4$; Fig. 2A). The most abundant cell type in our sample was the oriens-radiatum cell (OR; $n=16$; Fig. $2 A$ ). Their smooth or spiny dendrites were present in the stratum oriens, although their rarely ramifying axons could be observed typically in the strata oriens and radiatum, and occasionally penetrating into the CA1 region. These GABAergic neurons resemble those that project outside the hippocampus (Gulyás et al., 2003; Jinno et al., 2007). Radiatum cells (RAD, $n=9$ ) were sampled either in slices prepared from the GAD65-EGFP mice $(n=5)$, or from wild-type mice $(n=4$; Fig. $2 A)$. In both cases, the smooth dendrites of these interneurons as well as their axon arbor were found largely in the stratum radiatum and partially in stratum lucidum, rarely penetrating into the stratum oriens. The last distinguished neuron type was the ivy cell $(n=5$; see Fig. $5 C)$. The somata and the extension of the dendritic tree of ivy cells were smaller than those observed for other neurons. Their cell bodies were found in the stratum pyramidale or in its close vicinity. Their smooth dendrites as well as their axons ramified extensively around the somata, forming a dense local meshwork, but these cells do not express either PV or cholecystokinin, a marker of CB1 + BCs (Fuentealba et al., 2008). In this study, we have not recorded any bistratified cells in CA3, which interneuron type was described first in CA1 (Buhl et al., 1994).

\section{Firing behavior of CA3 neurons during SWRs}

Overall, we observed that only the minority of pyramidal cells fired during SWRs. From 59 pyramidal cells tested (16 was verified with biocytin labeling, whereas the others using DIC image), 10 neurons, all labeled intracellularly, discharged single action 
A

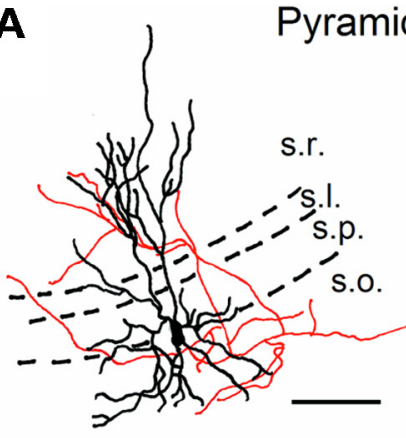

PV-positive axo-axonic cell

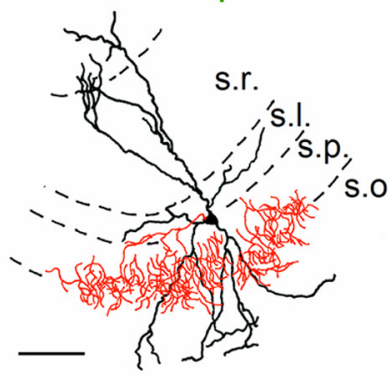

O-LM cell
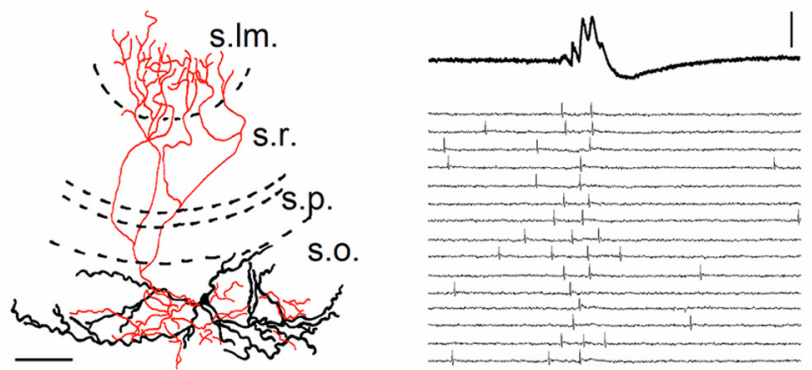

Oriens-radiatum cell

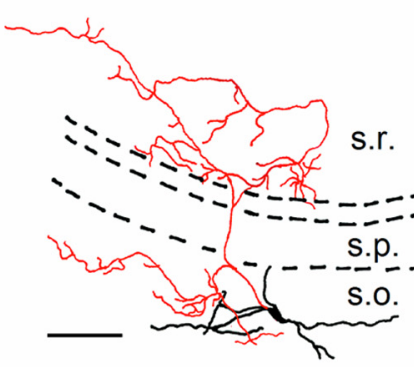

B
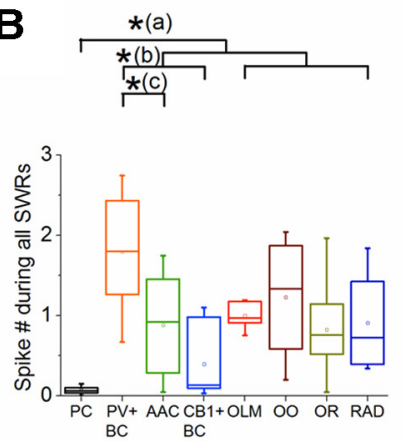
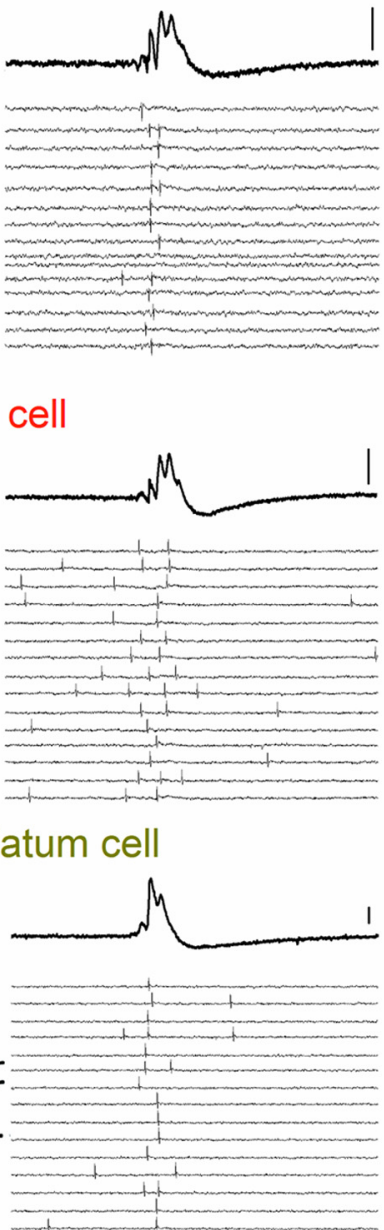

C
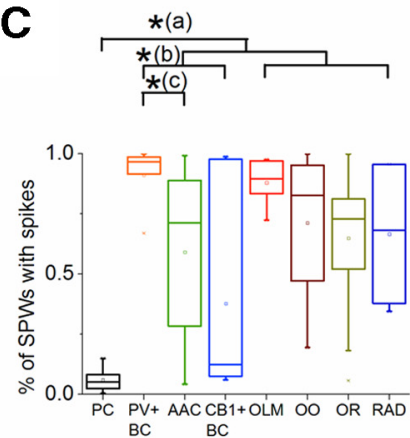

PV-positive basket cell
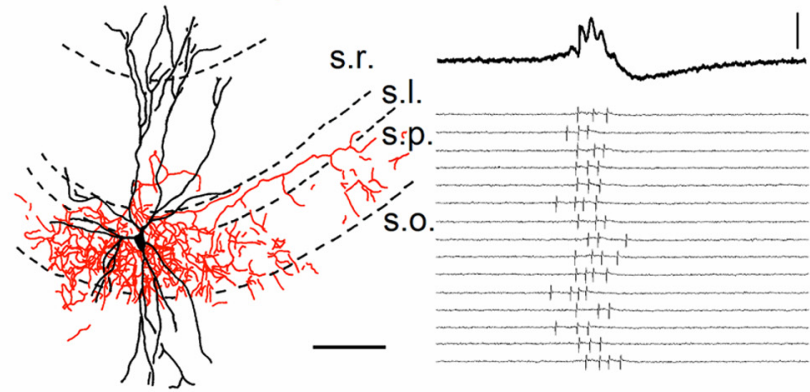

CB1-positive basket cell
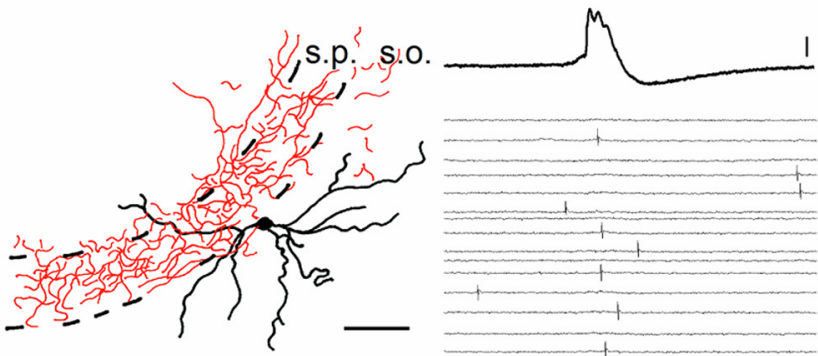

\section{Oriens-oriens cell}

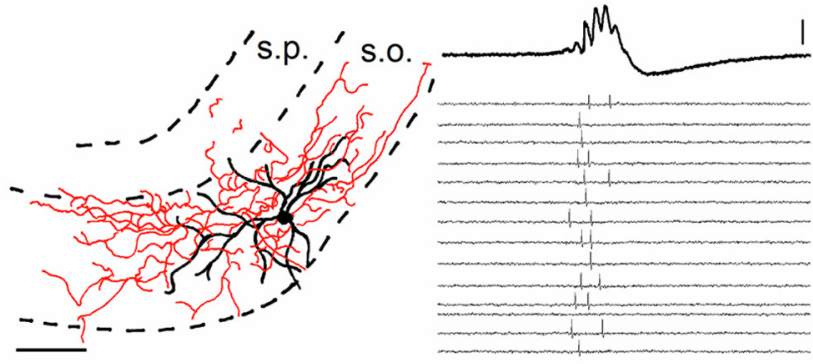

Radiatum cell
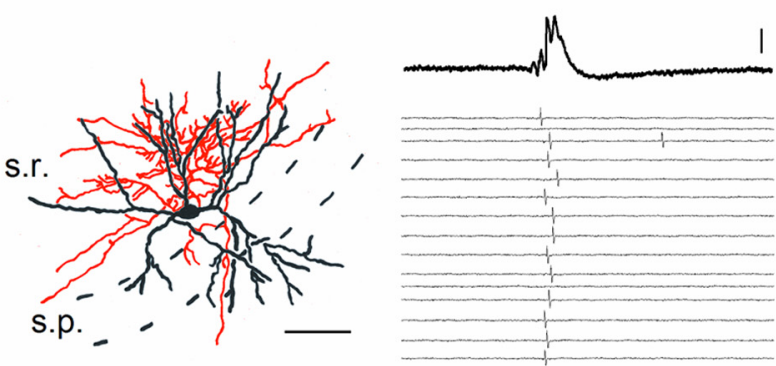

D

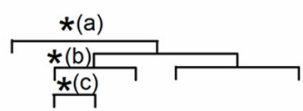

E
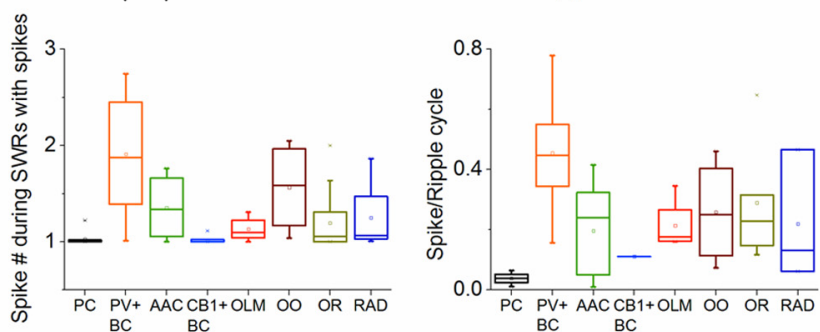

Figure 2. Firing properties of anatomically identified neurons in CA3 during SWRs. $A$, Camera lucida reconstructions of intracellularly labeled neurons from each group are presented (dendrites, black; axon, red). Scale bars, $100 \mu \mathrm{m}$. Spiking of individual neurons detected in loose patch mode was concomitantly recorded with SWRs. The firing activity of neurons during 15 consecutive SWRs are shown below the averaged SWRs (calculated from 50 events) for each case. Individual spikes are the positive deflections on the traces. Scale bar, $50 \mu \mathrm{V}$. $\boldsymbol{B}, \mathrm{PC}$ (Figure legend continues.) 
potentials during $\sim 6 \%$ of these synchronous events on average. In contrast, the majority of interneurons (77\%; 55/71) emitted one or more spikes during SWRs. The firing activity of interneurons showed cell type-specific behavior. Between SWRs, interneurons were more active than pyramidal cells $(\mathrm{M}-\mathrm{W}$ test, $p<$ 0.001 ), whereas the firing rate of perisomatic region-targeting interneurons $(\mathrm{PV}+\mathrm{BC}, \mathrm{AAC}, \mathrm{CB} 1+\mathrm{BC})$ and dendritic layerinnervating interneurons (OLM, OO, OR, RAD) did not differ (M-W test, $p=0.22$ ). During SWRs, pyramidal cells emitted the least number of spikes compared with all interneurons (Fig. $2 B$; Table $1 ; t$ test, $p<0.001)$. Similarly to the averaged spiking activity between SWRs, perisomatic region-targeting interneurons fired comparable number of spikes during SWRs than dendritic layer-innervating interneurons (Fig. $2 B$; Table 1 ; $t$ test, $p=0.44$ ). In the former cell groups, however, $\mathrm{PV}+\mathrm{BC}$ s spiked more during SWRs than AACs and CB1+BCs (ANOVA, $p<0.001$ ), whereas in the latter group the number of spikes did not differ in cell categories (ANOVA, $p=0.62$; Fig. $2 B$; Table 1 ). The only interneuron type, which did not spike during SWRs, was the ivy cell $(n=5)$. Among CB1 + BCs and RAD cells we found a substantial number of cells being silent during SWRs.

We calculated the probability of firing for all cell types during SWRs. The active pyramidal cells fired single action potentials during smaller portion of these synchronous events than interneurons ( $\mathrm{M}-\mathrm{W}$ test, $p<0.001$ ), but the perisomatic regiontargeting interneurons and dendritic layer-innervating interneurons did not differ in this respect $(\mathrm{M}-\mathrm{W}$ test, $p=0.54)$. However, there was a significant difference in the proportion of SWRs with spikes between basket cells and AACs (ANOVA, $p=$ $0.01)$, but not between interneurons innervating the dendritic layers (ANOVA, $p=0.46$; Fig. 2C; Table 1). In the former cell class, $\mathrm{PV}+\mathrm{BCs}$ fired on the larger portion of SWRs than AACs or $\mathrm{CB} 1+\mathrm{BCs}$ (Fig. 2C; Table 1). We then analyzed the number of spikes during those SWRs when the cell fired. We found that

\footnotetext{
$\leftarrow$

(Figure legend continued.) discharged the lowest number of spikes during SWRs than interneurons ( $\boldsymbol{B a}, p<0.001)$; perisomatic region-targeting interneurons and dendritic layerinnervating interneurons emitted similar number of spikes on average $(p=0.44) ; \mathrm{PV}+\mathrm{BC}$ spiked more than $A A C s$ and $C B 1+B C s(B \boldsymbol{b}, p<0.001$ for $P V+B C$ vs $C B 1+B C ; B C, p=0.005$ for $\mathrm{PV}+\mathrm{BC}$ vs $A A(s ; p=0.14$ for $A A C$ vs $(B 1+B C)$; no difference was found in cell types innervating the dendritic layers $(p=0.62)$. C, Although perisomatic region-targeting interneurons and dendritic layer-innervating interneurons fired similarly during most $\operatorname{SWRs}(p=$ $0.54), P(s$ only spiked during smaller proportion, $\sim 6 \%$ of these synchronous events on average $(\mathbf{C a}, p<0.001)$. Again, perisomatic region-targeting interneurons and dendritic layerinnervating interneurons emitted similar number of spikes on average $(p=0.54) ; \mathrm{PV}+\mathrm{BCs}$ spiked more than $\mathrm{AACs}$ and $\mathrm{CB} 1+\mathrm{BC}(\boldsymbol{C}(\boldsymbol{b}, p=0.003$ for $\mathrm{PV}+\mathrm{BC}$ vs $\mathrm{CB} 1+\mathrm{BC} ; \boldsymbol{C}, p=0.04$ for $\mathrm{PV}+\mathrm{BC}$ vs $\mathrm{AAC} ; p=0.19$ for $\mathrm{AAC}$ vs $(\mathrm{B} 1+\mathrm{BC})$; no difference was found in cell types innervating the dendritic layers $(p=0.46)$. $\boldsymbol{D}$, Compared with all interneurons, pyramidal cells fired less action potentials during those SWRs, when the cell fired ( $\boldsymbol{D a}, p<0.001$ ), while in perisomatic region-targeting interneurons and dendritic layer-innervating interneurons number of spikes emitted did not differ $(p=0.082)$. Among perisomatic region-targeting interneurons, $\mathrm{PV}+\mathrm{BC}$ s spiked more than $\mathrm{AACs}$ and $\mathrm{CB} 1+\mathrm{BC}(\boldsymbol{D b}, p<0.001$ for $\mathrm{PV}+\mathrm{BC}$ vs $\mathrm{CB} 1+\mathrm{BC}, p=$ 0.008 for $P V+B C$ vs $A A C s ; p=0.12$ for $A A C$ v $(B 1+B C)$, whereas no difference was found in cell types innervating the dendritic layers $(p=0.21)$. $\boldsymbol{E}$, Pyramidal cells emitted significantly less spikes during ripple cycles than interneurons ( $E a, p=0.014$ ), whereas perisomatic regiontargeting interneurons and dendritic layer-innervating interneurons discharged similar number of spikes $(p=0.36)$. In addition, PV + BCs discharged more spike during a ripple cycle than $\operatorname{AACs}(\boldsymbol{E b}, p=0.005)$, but cell types in the dendritic layer-innervating group discharged similar number of action potentials. In this graph only those neurons were included where the phasecoupling was significant (Rayleigh probability test; $p_{r}<0.05$ ). Here on the box charts and in Figures 4, 5, 7, the mean (small open square), the median (midline of the big box), the interquartile range (large box), the $5 / 95 \%$ values (end of the whiskers), and the minimal/maximal values (bottom and top X symbols) are shown. Asterisk labels the significant differences. See Table 1 for details.
}

pyramidal cells fired less action potentials compared with all interneurons (Fig. 2D; Table 1; M-W test, $p<0.001$ ). In addition, the perisomatic region-targeting interneurons tended to fire more action potentials than dendritic layer-innervating interneurons, although the difference did not reach significance $(\mathrm{M}-\mathrm{W}$ test, $p=0.08)$. Among perisomatic region-targeting interneurons, $\mathrm{PV}+\mathrm{BCs}$ fired significantly more spikes during a SWR than AACs or CB1 + BCs (ANOVA, $p<0.001$ ), whereas no difference was found in case of cell types innervating the dendritic layers (K-W ANOVA, $p=0.21$; Fig. $2 D$; Table 1 ). Next, we calculated the number of spikes during a ripple cycle by dividing the number of all spikes detected during ripple oscillations with the number of ripple cycles. We found no example for cells discharging more than a spike per a ripple cycle; therefore, this value gives the probability of discharge during a ripple cycle. In this analysis only those cells were included, whose firing was significantly phase-coupled $\left(p_{r}<0.05\right)$ to the ripple cycles determined with Rayleigh probability test. Similarly to what we found for SWRs, pyramidal cells were significantly less active during ripple oscillations than interneurons ( $\mathrm{M}-\mathrm{W}$ test, $p=0.014)$. Furthermore, we found that the spike number during a ripple cycle was similar for interneurons innervating the perisomatic or dendritic layers of pyramidal cells, when comparing these two functionally distinct groups ( $\mathrm{M}-\mathrm{W}$ test, $p=0.36$ ). The comparison of the number of spikes during a ripple cycle within these two groups uncovered that PV $+\mathrm{BCs}$ discharged more spikes than AACs $(t$ test, $p=0.005)$, but cell types in the dendritic layer-innervating group did not differ (K-W ANOVA, $p=0.88$; Fig. $2 E$; Table 1 ).

In the following sets of analysis we constructed the spike distribution histograms for each active neuron relative to the peak of the sharp wave envelop (zero point on the $x$-axis). The histograms were skewed toward the left with different extent, indicating that neurons tend to fire before the peak of the SWRs. The asymmetry in spike distribution histograms differed between pyramidal cells and interneurons $(\mathrm{M}-\mathrm{W}$ test, $p<0.001)$, but not between perisomatic region-targeting interneurons and dendritic layer-innervating interneurons ( $\mathrm{M}-\mathrm{W}$ test, $p=0.72)$. Although there was no difference in the asymmetry in spike distribution histograms among dendritic layer-innervating interneurons (K-W ANOVA, $p=0.13$ ), basket cells and AACs differed in this respect (K-W ANOVA, $p=0.02$; Fig. $3 A$; Table 1). Namely, the asymmetry was less pronounced for AACs than for $\mathrm{PV}+\mathrm{BCs}(p=0.004$; Table 1$)$. Other comparisons showed no significant differences $(p=0.46$ for $\mathrm{PV}+\mathrm{BCs}$ vs $\mathrm{CB} 1+\mathrm{BCs} ; p=$ 0.22 for AACs vs CB1+BCs; Table 1$)$. When the zero point on the $x$-axis of the histograms was set to the largest negative peak of the ripple oscillation, the plots showed more symmetric appearance in most cases, because the peak of ripple power always preceded the peak of SWRs by $1.43 \pm 0.41 \mathrm{~ms}(n=61$; Fig. $3 B)$. We also calculated the phase and the coupling strength of the firing relative to the negative peak of ripple oscillation. Four of the 10 pyramidal cells that fired had phase-coupled spikes $\left(p_{r}<0.05\right)$. Among perisomatic region-targeting interneurons, all $\mathrm{PV}+\mathrm{BCs}$, all, but one $\mathrm{AAC}$, and one of the $\mathrm{CB} 1+\mathrm{BCs}$ showed phasecoupled firing $\left(p_{r}<0.05\right)$. The firing of OLM cells, OO cells and half of the OR cells were comparably coupled to the ripple oscillation, whereas RAD cells were weakly phase coupled (Fig. $3 B, C$; $p_{r}<0.05$; Table 1). Circular statistical analysis revealed that the mean phase of spiking of all neurons was significantly different (Watson-Williams $F$ test for phase data, $p=0.013$; Table 1), namely, pyramidal cell fired at the distinct phase of ripple oscillations compared with all interneurons $(p<0.05)$. In contrast, the coupling strength of spiking was similar in all cell types 

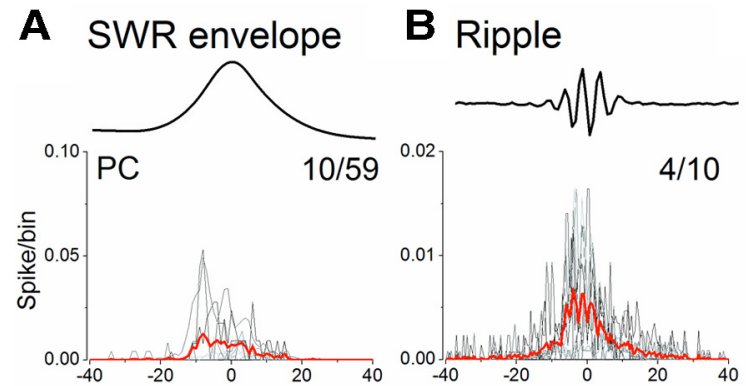

\section{Spike phase to neg. ripple cycles}
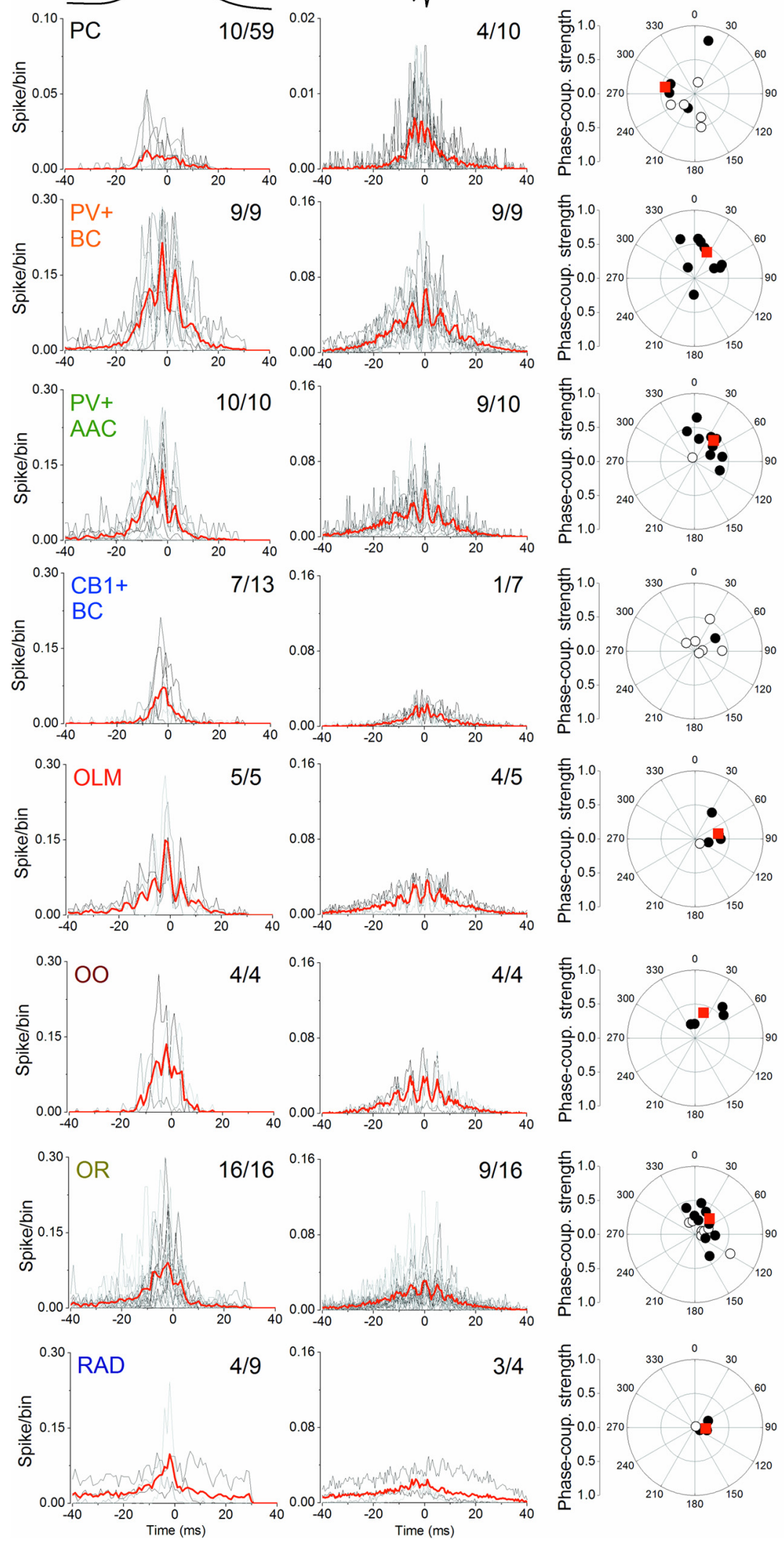

$3 / 4$
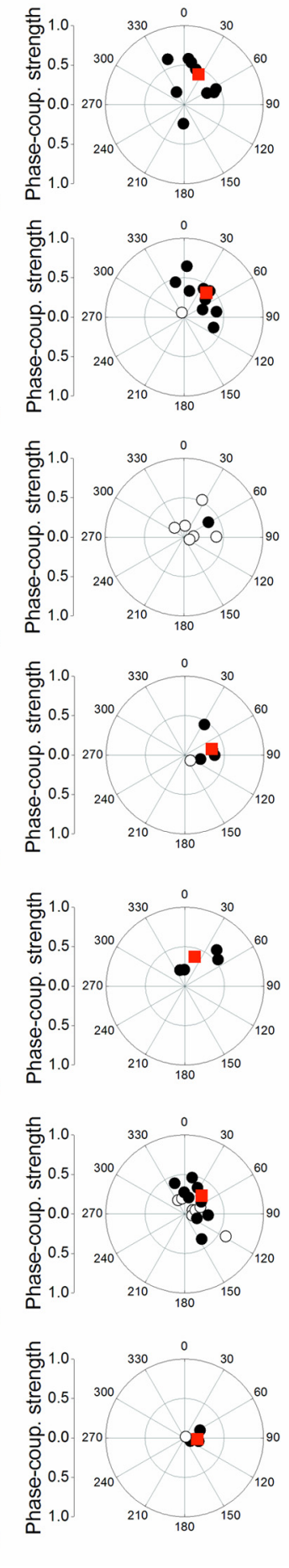

Figure 3. Spike distribution histograms of CA3 neurons during SWRs. A, Spike distribution histograms shown for individual neurons (gray) and their average (red) relative to the peak of the SWR envelop. In some neuron types, the asymmetry of the spike histograms relative to the SWR envelop peak is pronounced. Numbers in the top-right indicate the number of neurons that

(ANOVA for vector data, $p=0.14$; Fig. $3 C$; Table 1). In addition, we also calculated the spike time of spikes relative to the negative peak of ripple oscillation and found, in line with above data, that spike times were different (Table 1; ANOVA, $p=0.01$ ). Again, pyramidal cells fired earlier compared with the firing of the other cell types $(p<0.05)$.

These data show that in slices only a small fraction of excitatory pyramidal cells is active during SWRs, rarely emitting single action potentials, which occur at different phase of ripple oscillations than the spikes in interneurons. In contrast, interneurons usually spike during every SWR. Among all interneurons, $\mathrm{PV}+\mathrm{BCs}$ fired the most action potentials, whereas other GABAergic cells discharged similar number of spikes during SWRs.

\section{Synaptic currents in CA3 neurons during SWRs}

Following the detection of spikes in loosepatch mode, we recorded synaptic currents from the same neurons in whole-cell patch-clamp mode with a different pipette (Fig. 4; see Materials and Methods). EPSCs were recorded at the reversal potential of IPSCs, (between -85 and -75 $\mathrm{mV}$ ) determined experimentally for each neuron, whereas IPSCs were measured close to the reversal potential of EPSCs (between 0 and $+20 \mathrm{mV}$ ). To be able to compare the synaptic inputs for individual cells recorded at different holding potentials, we calculated the synaptic conductance (see Materials and Methods) and used these values in the further analysis. First we analyzed the recordings only for those neurons that spiked during SWRs. In this dataset, we observed that the synaptic excitation recorded in pyramidal cells was smaller than those measured in interneurons (Fig. 4B; Table 2; $\mathrm{M}-\mathrm{W}$ test, $p=0.003$ ), whereas the magnitude of excitatory postsynaptic conductance (EPSG) was similar in perisomatic region-targeting interneurons and dendritic layer-innervating inhibitory cells

discharged during SWRs from all recorded and anatomically identified neurons. $\boldsymbol{B}$, Spike distribution histograms for each neuron (gray) and their average (red) relative to the peak of the largest negative ripple cycle. Numbers in the upper right indicate the number of neurons whose spiking was phasecoupled to ripple oscillation (Rayleigh probability test; $\left.p_{r}<0.05\right)$. C, Polar plots indicate the phase and the strength of the ripple phase-coupled (black circle) and nonphase coupled (open circle) individual neurons. Red circle indicates the mean phase and strength calculated only from data of phasecoupled cells. See Table 1 for details. 


\section{A Pyramidal cell}
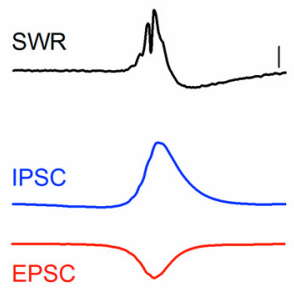

O-LM cell
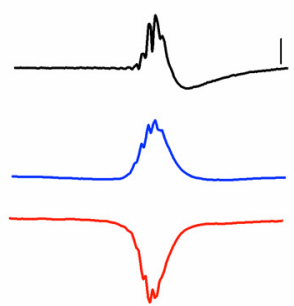

B

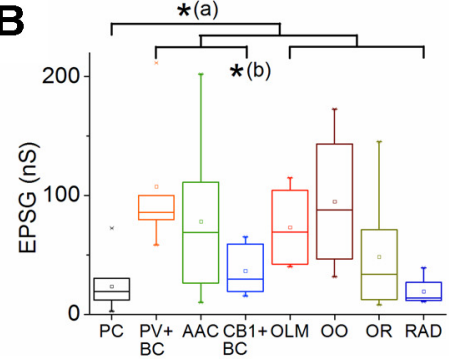

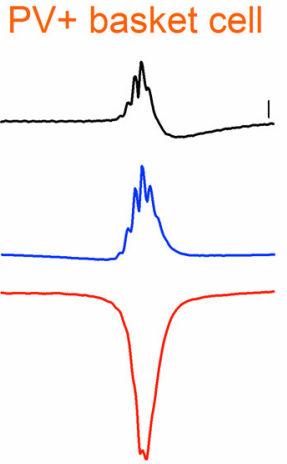

Oriens-oriens cell
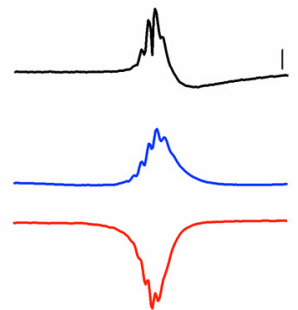

C

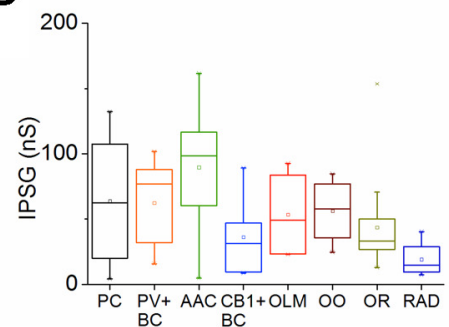

$\mathrm{PV}+$ axo-axonic cell
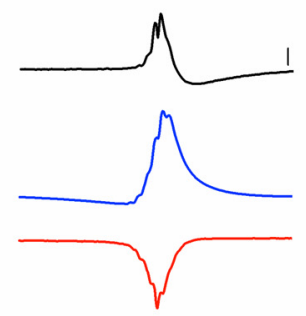

Oriens-radiatum cell
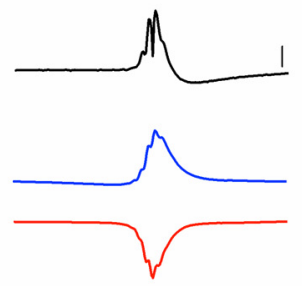

CB1+ basket cell
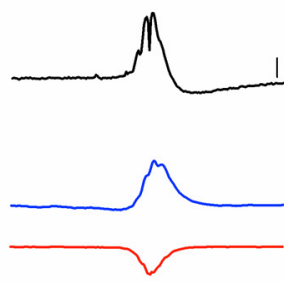
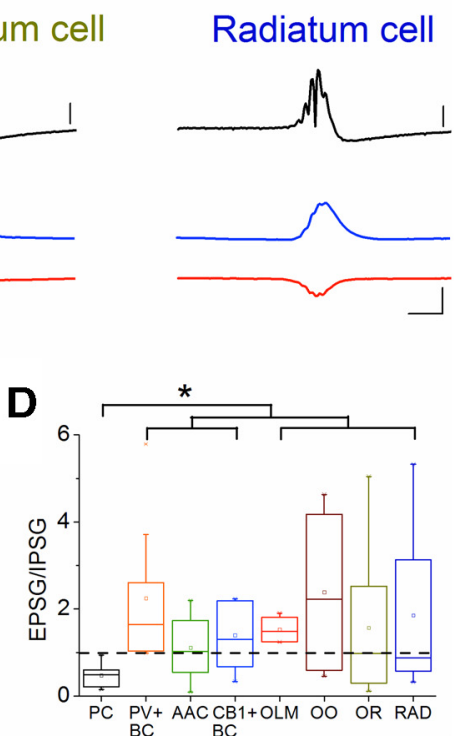

Figure 4. Excitatory and inhibitory synaptic inputs during SWRs. $\boldsymbol{A}$, For each cell type, averaged SWRs, EPSCs recorded at holding potentials between -75 and $-85 \mathrm{mV}$ and IPSCs at 0 and +20 $\mathrm{mV}$ are shown. These traces were calculated from the averaged traces obtained in all neurons that spiked during SWRs (EPSC, red; IPSC, blue). Scale bars, $50 \mu \mathrm{VV}$ for SWRs; $100 \mathrm{pA}$ and $25 \mathrm{~ms}$ for PSCs. $\boldsymbol{B}$, EPSG recorded during SWRs was significantly smaller in pyramidal cells than in interneurons ( $\mathbf{B a}, p=0.003)$, whereas EPSG was similar in perisomatic region-targeting interneurons and dendritic layer-innervating inhibitory cells ( $p=0.14)$. Furthermore, EPSGs recorded in CB1 + BCs were smaller in magnitude than in $\mathrm{PV}+\mathrm{BCs}(\boldsymbol{B} \boldsymbol{b}, p=0.008)$, while other comparisons did not reveal any differences between perisomatic region-targeting interneurons ( $p>0.3$ ), or between those cell groups targeting the dendritic region of pyramidal cells ( $p=0.066$ ). $C$, IPSG during SWRs was similar in pyramidal cells and interneurons. $\boldsymbol{D}$, The ratio of EPSG and IPSG during SWRs was smaller for PCs than those calculated for interneurons ( $p<0.001)$, but in interneurons there was no significant difference in this ratio $(p=0.69)$. See Table 2 for details.

Table 2. Properties of synaptic inputs recorded in distinct types of neurons during SWRs

\begin{tabular}{|c|c|c|c|c|c|c|c|c|}
\hline & PC & $\mathrm{PV}+\mathrm{BC}$ & AAC & $\mathrm{CB} 1+\mathrm{BC}$ & OLM & 00 & $O R$ & RAD \\
\hline & \multicolumn{8}{|c|}{ Active cells during SWRs } \\
\hline & $n=10$ & $n=9$ & $n=8$ & $n=7$ & $n=4$ & $n=4$ & $n=16$ & $n=4$ \\
\hline EPSG during SWRs (nS) & $23.5 \pm 6.2$ & $107.5 \pm 17.4$ & $78.1 \pm 23.1$ & $36.5 \pm 7.6$ & $73.2 \pm 18.5$ & $94.9 \pm 31.1$ & $48.4 \pm 10.5$ & $19.3 \pm 6.6$ \\
\hline IPSG during SWRs (nS) & $63.8 \pm 15.1$ & $62.4 \pm 10.3$ & $89.6 \pm 17.3$ & $36.3 \pm 10.5$ & $53.5 \pm 17.8$ & $56.2 \pm 13.1$ & $43.6 \pm 8.3$ & $19.2 \pm 7.3$ \\
\hline \multirow[t]{3}{*}{ EPSG/IPSG during SWRs } & $0.47 \pm 0.08$ & $2.25 \pm 0.54$ & $1.11 \pm 0.26$ & $1.39 \pm 0.29$ & $1.53 \pm 0.16$ & $2.38 \pm 1.06$ & $1.57 \pm 0.37$ & $1.85 \pm 1.16$ \\
\hline & \multicolumn{8}{|c|}{ Silent cells during SWRs } \\
\hline & $n=7$ & $n=0$ & $n=0$ & $n=6$ & $n=0$ & $n=0$ & $n=0$ & $n=4$ \\
\hline EPSG during SWRs (nS) & $21.7 \pm 2.9$ & NA & NA & $8.2 \pm 1.6$ & NA & NA & NA & $5.1 \pm 2.3$ \\
\hline IPSG during SWRs (nS) & $127.3 \pm 21.6$ & NA & NA & $34.8 \pm 7.9$ & NA & NA & NA & $36.4 \pm 12.8$ \\
\hline EPSG/IPSG during SWRs & $0.21 \pm 0.04$ & NA & NA & $0.32 \pm 0.11$ & NA & NA & NA & $0.16 \pm 0.06$ \\
\hline
\end{tabular}

Data are presented as mean \pm SEM. NA, Not applicable.

(Fig. 4B; Table 2; $\mathrm{M}-\mathrm{W}$ test, $p=0.14$ ). A more detailed analysis revealed that the synaptic excitation received by distinct types of perisomatic region-targeting interneurons was different $(\mathrm{K}-\mathrm{W}$ ANOVA, $p=0.01)$. EPSGs recorded in CB1+ BCs during SWRs were smaller in magnitude than in PV+ BCs $(p=0.008)$, whereas other comparisons between those cell groups targeting the perisomatic region of pyramidal cells uncovered no difference $(p>0.3)$. In dendritic layer-innervating interneurons the magnitude of EPSG was found not to be distinct using K-W ANOVA test $(p=0.066)$. In contrast to synaptic excitation, the 

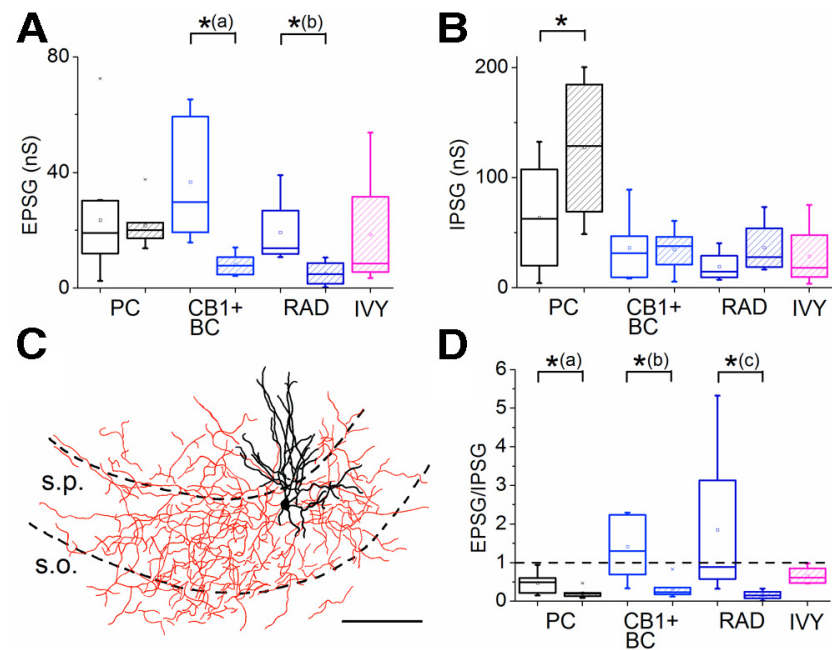

Figure 5. Comparison of synaptic conductances during SWRs in spiking and nonspiking neurons. A, EPSG during SWRs was similar in spiking and nonspiking pyramidal cells, but spiking interneurons received larger synaptic excitation than their nonspiking pairs (open, spiking neurons; dashed, nonspiking neurons, $\boldsymbol{A a}, p=0.005 ; \boldsymbol{A} \boldsymbol{b}, p=0.03)$. Only nonspiking ivy cells were observed $(n=5)$. $\boldsymbol{B}$, IPSG measured during SWRs was significantly smaller in spiking pyramidal cells than in nonspiking ones ( $p=0.02)$; however, there was no difference in IPSG magnitude in interneurons. C, A camera lucida reconstruction of an ivy cell (dendrites, black; axon, red). Scale bar, $100 \mu \mathrm{m}$. D, Larger EPSG to IPSG ratio characterizes spiking than nonspiking cells. This ratio was significantly larger for pyramidal cells ( $\boldsymbol{D a}, p=0.02)$, for CB1+BCs $(\boldsymbol{D b}, p=0.008)$ and for RAD cells ( $\boldsymbol{D} \boldsymbol{c}, p=0.048)$. EPSG/PSG ratio for ivy cells was below one. See Table 2 for details.

synaptic inhibition measured during SWRs was similar in pyramidal cells and interneurons (Fig. 4C; Table 2; $\mathrm{M}-\mathrm{W}$ test, $p=$ 0.69 ), and the magnitude of inhibitory postsynaptic conductance (IPSG) during SWRs received by perisomatic region-targeting interneurons was comparable to that recorded in dendritic layerinnervating interneurons ( $\mathrm{M}-\mathrm{W}$ test, $p=0.065$ ), as well as within these broad cell categories the synaptic inhibition was similar (K-W ANOVA, $p=0.07$ for perisomatic region-targeting interneurons and $p=0.13$ for dendritic layer-innervating interneurons). The ratio of excitation to inhibition in pyramidal cells was $<1$ (Fig. $4 D$; Table 2), indicating that the inhibitory synaptic input is dominant in these neurons during SWRs. The ratio of EPSG and IPSG in interneurons was $\sim 1$ or was larger, suggesting that synaptic excitation is prevailing in GABAergic cells during SWRs (Fig. 4D; Table 2). EPSG/IPSG ratio obtained in pyramidal cells was significantly smaller than those calculated for interneurons (M-W test, $p<0.001$ ), whereas among interneurons there was no significant difference in this ratio $(\mathrm{M}-\mathrm{W}$ test, $p=0.69$ for the comparison between perisomatic regiontargeting interneurons and dendritic layer-innervating interneurons; $\mathrm{K}-\mathrm{W}$ ANOVA, $p=0.16$ and $p=0.82$ for the group of perisomatic region-targeting interneurons and dendritic layerinnervating interneurons, respectively).

Next, we calculated the synaptic inputs in neurons, which were silent during SWRs, and the results were compared with those cells that were active (Fig. 5; Table 2). Such analysis could be made for pyramidal cells, CB1+BCs and RAD cells. We found that the synaptic excitation was similar in active and silent pyramidal cells $(t$ test, $p=0.82$ ), but it was significantly larger in spiking interneurons compared with their silent pairs $(t$ test, $p=0.005$ for $\mathrm{CB} 1+\mathrm{BCs}$; $\mathrm{M}-\mathrm{W}$ test, $p=0.03$ for RAD cells). On the contrary, significantly smaller synaptic inhibition was received by those pyramidal cells that spiked during SWRs than the silent ones ( $t$ test, $p=0.02$ ), whereas IPSG in the active and silent interneurons was comparable ( $t$ test, $p=0.92$ for $\mathrm{CB} 1+\mathrm{BCs} ; p=0.29$ for RAD cells). Therefore, the ratio of EPSG/IPSG in spiking cells in each cell type was larger than in silent cells $(t$ test, $p=0.02$ for pyramidal cells; $t$ test, $p=0.008$ for $\mathrm{CB} 1+\mathrm{BCs}$; $\mathrm{M}-\mathrm{W}$ test, $p=0.048$ for RAD cells). Thus, smaller synaptic inhibition resulted in larger EPSG/IPSG ratio in spiking pyramidal cells compared with silent ones, whereas larger synaptic excitation was detected in spiking interneurons than in their silent pairs during SWRs.

We also examined the synaptic inputs of ivy cells during SWRs. These interneurons, which were uniformly silent during SWRs, received smaller synaptic excitation (EPSG: $18.6 \pm 11.8$, $n=4$ ) than inhibition (IPSG: $28.7 \pm 15.9, n=4$ ), as reflected in their EPSG/IPSG ratio (E/IPSG: $0.66 \pm 0.12, n=4$; Fig. 5 ).

To gain deeper insights into the link between the synaptic inputs and the firing output of neurons during SWRs, we related the synaptic conductance with the number of spikes. Because the above data propose that the firing of pyramidal cells and interneurons during SWRs might be distinctly controlled by excitatory and inhibitory synaptic inputs, we investigated the input-output relationship separately. In pyramidal cells, we found no tendency between the EPSG and the number of spikes, between IPSG and the number of spikes, or between the EPSG/ IPSG ratio and the number of spikes during SWRs (Fig. 6A, C,E). In contrast, there was a strong correspondence between the magnitude of EPSG and the number of spikes in interneurons during these synchronous network events (Fig. 6B). Even though, no link was observed between the magnitude of IPSG and the number of spikes in interneurons (Fig. 6D), their EPSG/IPSG ratio still correlated with the number of spikes during SWRs (Fig. 6F).

In summary, in pyramidal cells the recorded inhibitory synaptic input dominates over the synaptic excitation during SWRs, whereas, in case of interneurons it is quite the opposite, excitatory synaptic input is larger than synaptic inhibition. The comparison of the inputs in active and silent cells during SWRs as well as the relationship between the magnitude of the synaptic inputs and spike numbers suggests that pyramidal cell firing can be controlled by synaptic inhibition fluctuating between SWRs, whereas the magnitude of the excitatory synaptic input regulates the spiking activity of interneurons.

\section{Comparison of the firing histograms and the temporal structure of synaptic inputs during SWRs}

Next, we asked whether the observed asymmetry in spike distribution histogram relative to the sharp wave peak envelop could be the result of the asymmetry in excitatory synaptic input, because excitation is a main determinant of spiking, at least in interneurons. To clarify this issue, we calculated the magnitude of EPSG and IPSG as well as their ratios for the period before the peak (pre-SWR peak) and after the peak (post-SWR peak) of sharp wave envelop (Fig. 7A). A weak, but significant correlation was observed in the asymmetry of spike distribution histogram with the ratio of EPSG before and after the peak of sharp wave envelops (Fig. 7B). No other comparison of the histogram asymmetry with additional parameters of synaptic inputs showed any significant link. These results propose that asymmetry in spiking during SWRs may be, at least in part, the consequence of the asymmetry in the excitatory synaptic input.

This detailed analysis also uncovered some additional interesting results. We observed substantial cell-type specific differences in inputs of those interneurons that have comparable soma-dendritic appearance in CA3 network and thus are expected to collect the same inputs. When we compared the temporal structure of SWR-related synaptic inputs of pyramidal cells 
and perisomatic region-targeting interneurons located close to the stratum pyramidale, which neurons have almost exclusively radial dendritic arbor spanning all layers and might receive synaptic inputs from the same sources during SWRs, we found that the magnitude of EPSG before the peak and after the peak of SWR was significantly different (ANOVA, $p<0.001$ and $p=0.004$, for pre-peak EPSG and post-peak EPSG, respectively; Fig. 7C,D; Table 3). The Fisher post hoc test confirmed that before the peak of SWRs PV + BCs received significantly larger synaptic excitation than pyramidal cells, AACs or CB1+BCs, a difference, which was similar also after the peak of SWRs (Fig. 7C,D; Table 3). EPSGs before, but not after, the peak of SWRs were larger in AACs than in pyramidal cells or $\mathrm{CB} 1+\mathrm{BCs}$ (Fig. 7C,D; Table 3). Consequently, the ratio of pre/post-SWR peak EPSG was larger for AACs, than for pyramidal cells, $\mathrm{PV}+\mathrm{BCs}$ or $\mathrm{CB} 1+\mathrm{BCs}$ on average (ANOVA, $p=0.001$; Fig. 7G; Table 3 ), indicating that in AACs the magnitude of the excitatory input is smaller after the peak of SWRs than before, which was opposite to that observed in pyramidal cells or basket cells. In addition to the excitatory input, there were some significant differences also in the temporal structure of synaptic inhibition after the peak of SWRs (post-peak IPSG, ANOVA, $p=$ 0.004 ), but not before it (pre-peak IPSG, ANOVA, $p=0.07$; Fig. $7 E, F)$. Namely, pyramidal cells and AACs received comparable IPSGs after the peak of SWRs, and, similarly, the two types of basket cells collected equal synaptic inhibition (Fig. 7F; Table 3). Moreover, after the SWR peak IPSGs in AACs were significantly larger than in the basket cells and IPSGs in pyramidal cells were larger than in $\mathrm{CB} 1+\mathrm{BCs}$ (Fig. 7F; Table 3). However, the ratio of pre/post-SWR peak IPSG was not different (ANOVA, $p=0.41$; Fig. $7 \mathrm{H}$; Table 3 ). When the ratio of EPSG/IPSG before the peak of SWRs was compared with the ratio of EPSG/IPSG after the peak, we found that $\mathrm{PV}+\mathrm{BC}$ s received larger excitation than inhibition before as well as after the SWR peak than pyramidal cells or other types of perisomatic region-targeting interneurons (ANOVA, $p<0.001$ and $p=0.002$ for pre-peak E/IPSG and post-peak E/IPSG, respectively; Fig. 7I,J; Table 3). Although the temporal structure of synaptic input did not changed in pyramidal cells or in basket cell (Fig. 7I,J), EPSG before the SWR peak in AACs was larger than IPSG, which was reversed after the SWR peak ( $t$ test, $p=0.004$ ).

In addition to perisomatic region-targeting interneurons, we also compared the fine structure of synaptic inputs during SWRs in interneurons with horizontal dendrites in the stratum oriens, because they might be innervated by the same afferents. Indeed, we found that in general these cells had comparable synaptic inputs before and after the SWR peak $(p>0.1)$ with two excep- tions. OLM cells received a slightly larger EPSG after the SWR peak than OR cells $(p=0.02)$, and IPSG was larger before the SWR peak in OO cells that in OR cells $(p=0.01$; Table 3$)$.

This detailed examination of synaptic inputs during SWRs suggest that, although dendritic layer-innervating interneurons located in the startum oriens receive comparable synaptic inputs during SWRs, in distinct types of GABAergic cells innervating the perisomatic region of pyramidal cells we measured significantly different synaptic excitation and/or inhibition during these population events, which might, at least in part, explain some of the differences in their spiking behavior.

\section{Interaction between excitatory and inhibitory synaptic conductances during SWRs}

In the last set of the analysis, we determined the combined effect of synaptic inputs during SWRs (Borg-Graham et al., 1998; de la Prida and Gal, 2004; Oren et al., 2006). To reveal the interaction between inhibitory and excitatory synaptic conductances, we cal- 

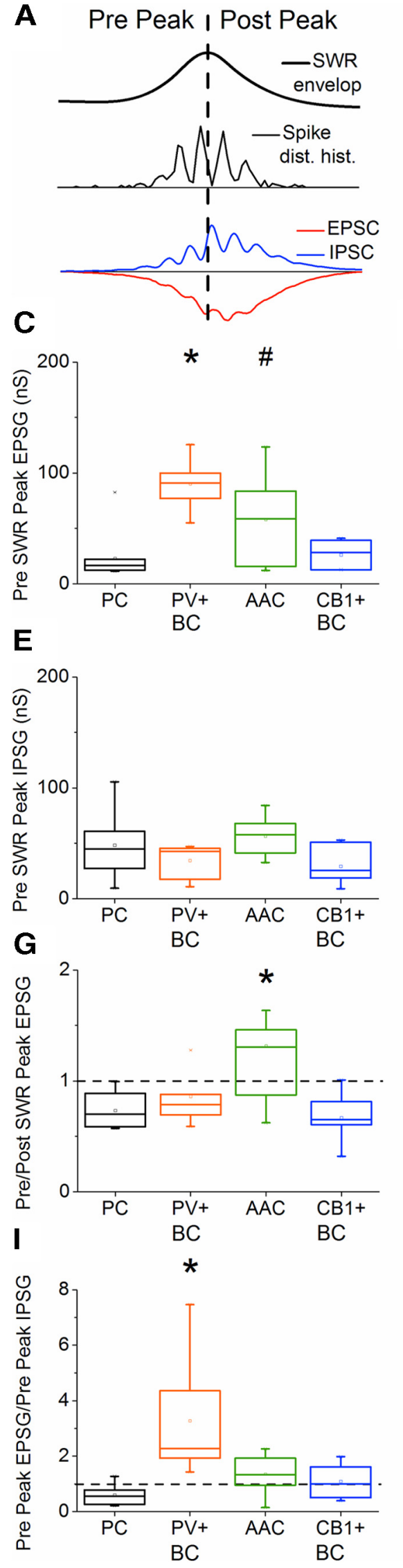

B

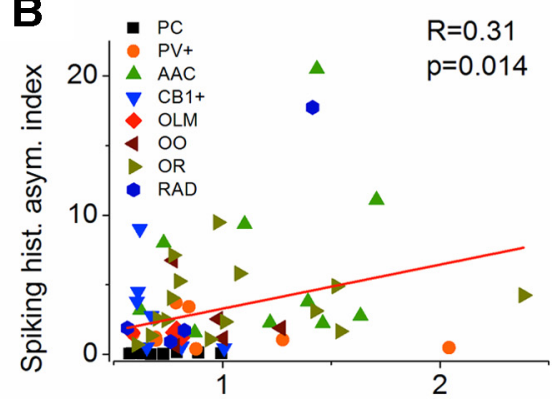

Pre/Post SWR Peak EPSG
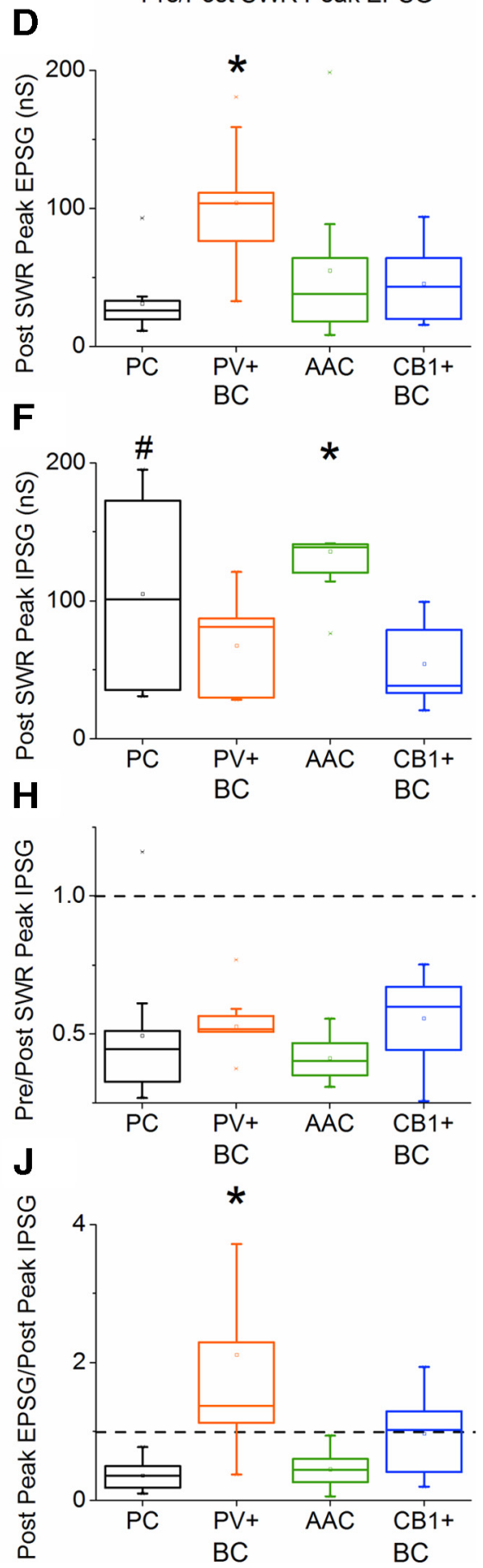

Figure 7. Temporal structure of synaptic inputs relative to the SWR peak. A, A spike distribution histogram, averaged EPSC and IPSC recorded in a PV + basket cell aligned to the SWR peak illustrates the method used to estimate the temporal structure of synaptic inputs and its correlation to spiking. $\boldsymbol{B}$, Pre/post-SWR Peak EPSG showed a weak, but significant correlation with the culated the net apparent synaptic reversal potential $E_{s y n}^{r e v}$ (see Materials and Methods). $E_{\text {syn }}^{\text {rev }}$ describes the effective synaptic conductance during these synchronous events, and thus, provides a measure of the balance of excitation and inhibition. We observed that the maximums and the minimums of the spike distribution histograms were tightly coupled to the peaks and the troughs in the "ripple"-like appearance of $E_{s y n}^{r e v}$, respectively, indicating that the excitatory and inhibitory synaptic conductances shape together the firing of interneurons during SWRs (Fig. 8A,B). In addition, we found that the averaged $E_{s y n}^{r e v}$ curves showed cell-type dependence both in their peak values and their appearance (Fig. 8C). In those cell groups, in which the peak of $E_{s y n}^{r e v}$ approached closer the reversal potential of the synaptic excitation, more spikes could be detected (Fig. $8 D$ ), confirming that the magnitude of excitatory synaptic input controls the spiking activity during SWRs, at least in interneurons. Moreover, the asymmetry in the spike distribution histograms relative to the sharp wave peak matched the asymmetry in $E_{s y n}^{r e v}$ as shown in examples in Figure $8 A, B$. At population levels, in $\mathrm{PV}+\mathrm{BCs}$ and OLM cells, in which interneuron types the asymmetry index of spike distribution histograms was close to 1 (Table 1), the appearance of the averaged $E_{s y n}^{r e v}$ curves was also more symmetric, whereas in other cell types the $E_{s y n}^{r e v}$ reached its maximum before or around the peak of

asymmetry in spike distribution histograms, indicating that asymmetry in excitatory input may, at least in part, account for the observed asymmetry in firing relative to the SWR peak. EPSG before the SWR peak (pre-SWR peak) (C), EPSG after the SWR peak (post-SWR peak) (D), IPSG before the SWR peak (pre-SWR Peak) (E), and IPSG after the SWR peak (post-SWR peak). $\boldsymbol{F}$ ), Distinct cell types with similar dendritic arborization are shown. $\boldsymbol{C}, \boldsymbol{D}, \mathrm{PV}+\mathrm{BC}$ s receive significantly larger EPSGs both before (*PC vs PV +BC, $p<0.001 ; \mathrm{PV}+\mathrm{BC}$ vs $\mathrm{AAC}, p=$ 0.014; $P V+B C$ cell vs $(B 1+B C, p<0.001 ;)$ and after SWR peak ( ${ }^{*} \mathrm{PC}$ vs $\mathrm{PV}+\mathrm{BC}, p<0.001 ; \mathrm{PV}+\mathrm{BC}$ vs $\mathrm{AAC}, p=0.01$; $P V+B C$ vs $C B 1+B C, p=0.008)$ compared with other cell types, whereas EPSGs in AACs are larger only before the SWR peak compared with pyramidal cells or $C B 1+B C s$ (\#PC vs $A A C$, $p=0.006 ; A A C$ vs $(B 1+B C, p=0.02)$. $\mathbf{G}$, The ratios of EPSG before and after the SWR peak in AACs were significantly larger than in other cells types ( ${ }^{*} P C$ vs $A A C, p<0.001$; $P V+$ $B C$ vs $A A C, p=0.008$; $A A C$ vs $(B 1+B C, p<0.001)$, whereas no difference was observed in the ratios of IPSG before and after the SWR peak $(\boldsymbol{H})$. EPSG to IPSG ratios before the SWR peak (I) or following the SWR peak ( $\boldsymbol{J}$ ) are significantly larger in $P V+B C s$ than in pyramidal cells, $A A C s$ or $C B 1+B C s\left(I,{ }^{*} P C\right.$ vs $\mathrm{PV}+\mathrm{BC}, p<0.001 ; \mathrm{PV}+\mathrm{BC}$ vs $\mathrm{AAC}, p=0.001 ; \mathrm{PV}+\mathrm{BC}$ cell vs $C B 1+B C, p<0.001 ; J$, ${ }^{*} P C$ vs PV $+B C, p<0.001 ; P V+B C$ vs $A A C, p=0.001 ; P V+B C$ cell vs $(B 1+B C, p=0.026)$. See Table 3 for details. 
Table 3. Properties of synaptic inputs before and after the peak of sharp wave envelop in distinct types of neurons during SWRs

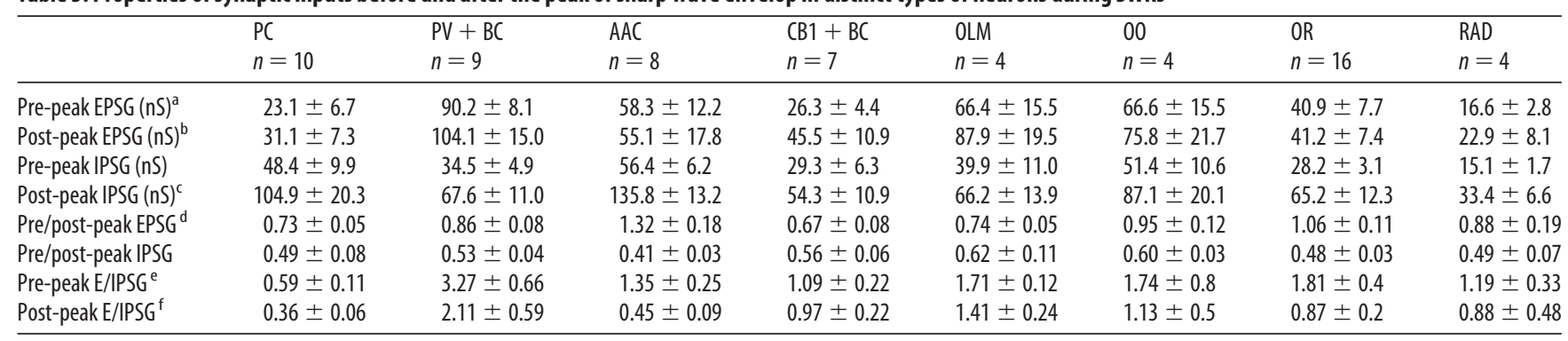

Data are presented as mean \pm SEM. Footnotes indicate the significant differences.

${ }^{a} P C$ versus $P V+B C, p<0.001 ; P C$ versus $A A C, p=0.006 ; P C$ versus $C B 1+B C, p=0.8 ; P V+B C$ versus $A A C, p=0.014 ; P V+B C$ cell versus $C B 1+B C, p<0.001 ; A A C$ versus $C B 1+B C, p=0.02$.

${ }^{b} P C$ versus $P V+B C, p<0.001 ; P C$ versus $A A C, p=0.2 ; P C$ versus $C B 1+B C, p=0.7 ; P V+B C$ versus $A A C, p=0.01 ; P V+B C$ versus $C B 1+B C, p=0.008 ; A A C$ versus $C B 1+B C, p=0.6$.

${ }^{C} P C$ versus $P V+B C, p=0.08 ; P C$ versus $A A C, p=0.15 ; P C$ versus $C B 1+B C, p=0.02 ; P V+B C$ versus $A A C, p=0.003 ; P V+B C$ versus $C B 1+B C, p=0.56 ; A A C$ versus $C B 1+B C, p=0.001$.

${ }^{d} P C$ versus $P V+B C, p=0.44 ; P C$ versus $A A C, p<0.001 ; P C$ versus $C B 1+B C, p=0.71 ; P V+B C$ versus $A A C, p=0.008 ; P V+B C$ versus $C B 1+B C, p=0.29 ; A A C$ versus $C B 1+B C, p<0.001$.

ePC versus $P V+B C, p<0.001 ; P C$ versus $A A C, p=0.16 ; P C$ versus $C B 1+B C, p=0.38 ; P V+B C$ versus $A A C, p=0.001 ; P V+B C$ cell versus $C B 1+B C, p<0.001 ; A A C$ versus $C B 1+B C, p=0.66$.

${ }^{f} P C$ versus $P V+B C, p<0.001 ; P C$ versus $A A C, p=0.85 ; P C$ versus $C B 1+B C, p=0.21 ; P V+B C$ versus $A A C, p=0.001 ; P V+B C$ cell versus $C B 1+B C, p=0.026 ; A A C$ versus $C B 1+B C, p=0.31$.

the sharp waves, followed by the abrupt drop toward more negative values (Fig. $8 C$ ). We calculated the asymmetry index of $E_{s y n}^{\text {rev }}$ in individual cells, similarly to the asymmetry index of spike distribution histograms (Fig. 7A). Although no relationship was observed between the asymmetry index of $E_{s y n}^{r e v}$ and the asymmetry index of spike distribution histograms in pyramidal cells (Fig. $8 E$ ), there was a strong correlation between these values in interneurons (Fig. $8 F$ ).

These results strengthen the idea that in interneurons the number of discharges during SWRs is primarily determined by the magnitude of synaptic excitation, and suggest that the spike distribution during these network events is shaped by the temporal dynamics of both excitatory and inhibitory synaptic inputs. The firing of pyramidal cells during SWRs, however, is controlled mainly by other factors.

\section{Discussion}

As in vivo studies uncovered, SWRs are generated in the CA3 region of the hippocampus (Csicsvari et al., 2000; Maier et al., 2003; Nakashiba et al., 2009). Within the same hippocampal area, population events with similar appearance can be recorded in rodent slices, where they occur spontaneously and when the content of aCSF is modified, respectively, or they are evoked by electrical stimulation (Kubota et al., 2003; Maier et al., 2003; Behrens et al., 2005; Wu et al., 2005; de la Prida et al., 2006; Ellender et al., 2010). Although these synchronous population events in slices are shorter in duration than those recorded in vivo, the in vitro SWRs share several features with their in vivo equivalents, including the emergence of a large deflection in LFP concomitant with high-frequency oscillation, the characteristic increase in firing rate of neurons during SWRs and the typical laminar profile of current sinks and sources during these events. These striking similarities in synchronous population events observed in slices with those recorded in vivo propose that the in vitro approach might serve as a model for in vivo SWRs, grabbing some of their key features.

In this study we found that only a small portion of pyramidal cells became active during SWRs and pyramidal cells discharge at different phases of the CA3 ripple oscillation than interneurons (Fig. 3), similar to in vivo results (Csicsvari et al., 2000; Sullivan et al., 2011). The low number of active pyramidal cells during SWRs in slices may be due to the smaller size of the neuronal ensemble generating these in vitro synchronous events compared with in vivo and/or the lack of extrahippocampal inputs, which could impact the amount of pyramidal cells recruited into these net- work activities. The firing activity of anatomically identified interneurons during in vivo SWRs is already known for CB1 + basket and dendritic layer-innervating cells from CA3 (Lasztoczi et al., 2011). Similarly to the data obtained in anesthetized rats, we observed in slices that $\mathrm{CB} 1+\mathrm{BCs}$ were only weakly recruited during SWRs, because only a part of these interneurons were found to spike, and if they spiked, single action potentials were detected at every third event on average. Comparable firing behavior was observed for dendritic layer-innervating cells. In addition, the firing behavior of distinct types of CA1 interneurons during SWRs is impressively similar to what we obtained in CA3 hippocampal slices. For instance, $\mathrm{PV}+\mathrm{BC}$ are one of the most active interneuron types, whereas ivy cells were found to be silent (Fuentealba et al., 2008; Lapray et al., 2012; Varga et al., 2012). Furthermore, OLM cells increase their firing under these population events in freely moving animals (Varga et al., 2012). The comparable spiking behavior of the anatomically identified neurons during SWRs in vitro and in vivo further strengthen the idea that the in vitro model can be used to reveal the synaptic mechanisms underlying the firing properties of distinct types of neurons.

\section{Synaptic inputs distinctly influences the firing of pyramidal cells and interneurons during SWRs}

One of our main observations in this study is that the synaptic inhibition is dominant in pyramidal cells during SWRs, whereas excitation dominates the synaptic inputs of active interneurons. Although the magnitude of recorded excitatory input in active and silent pyramidal cells was comparable, in the former group smaller inhibitory synaptic charge was measured than in the latter, indicating that synaptic inhibition plays a role in controlling the spiking of pyramidal cells during in vitro SWRs. In contrast, larger synaptic excitation was present in active interneurons than in nonspiking cells within the same anatomical categories. Moreover, there was a strong correlation between the magnitude of excitatory synaptic charge and the number of spikes during SWRs including all spiking interneurons (Figs. 6B, $8 D$ ). These data are reminiscent of those found in a previous study investigating the input-output properties of distinct classes of CA3 neurons during gamma oscillation in vitro (Oren et al., 2006). The strikingly similar observations in the synaptic mechanisms governing the firing behavior of excitatory and GABAergic neurons during gamma oscillations and SWRs propose that neurons are integrating similarly their synaptic inputs during these network states. However, it should be noted that in addition to the synaptic inputs the firing of 
A
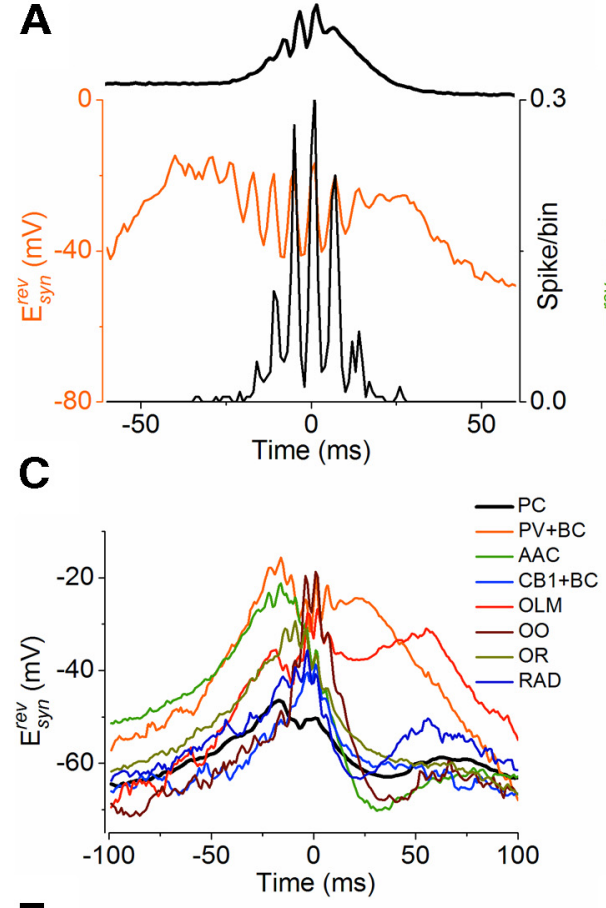

E
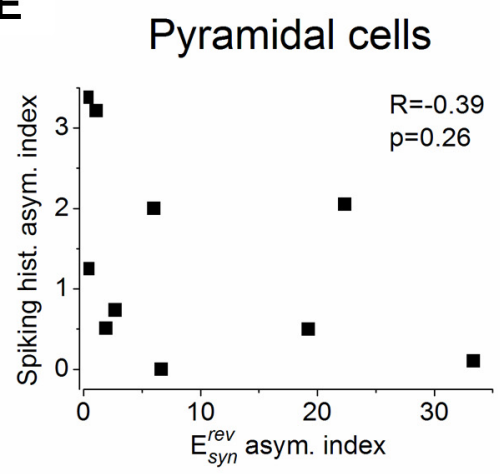

B

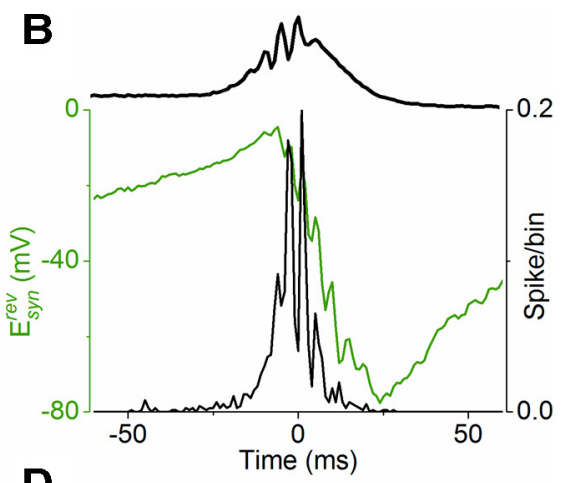

D
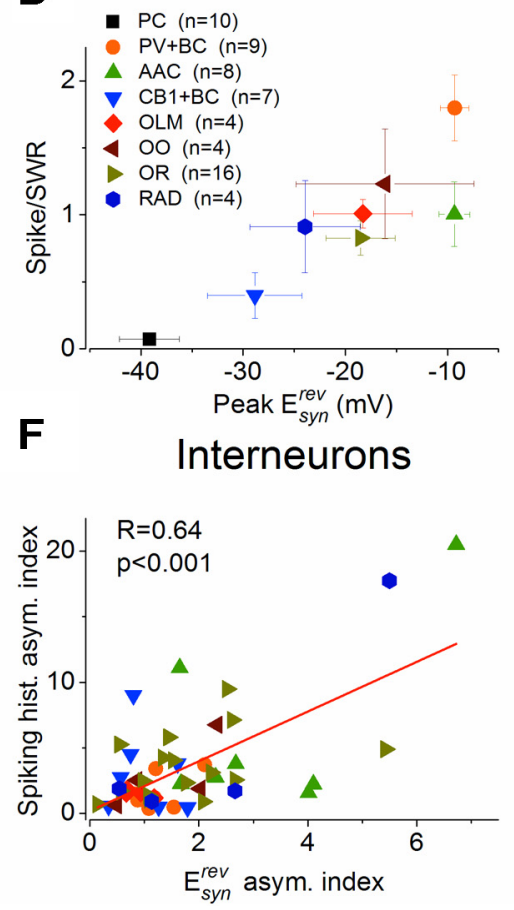

Figure 8. Interaction between excitatory and inhibitory synaptic conductances during SWRs. For a $P V+B C(\boldsymbol{A})$ and an $A A C(\boldsymbol{B})$, the net apparent synaptic reversal potential ( $E_{s y n}^{r e v}$ in color) and the spike distribution histogram during SWRs is overlaid (black). The maximums and the minimums of the spike distribution histograms are tightly coupled to the peaks and the troughs in the ripple-like appearance of $E_{s y n}^{r e v}$, respectively, indicating that the excitatory and inhibitory synaptic conductances shape together the firing of these interneurons during SWRs. In addition, the asymmetry in the spike distribution histograms relative to the sharp wave peak matches the asymmetry in $E_{s y n}^{r e v}$. Top, SWR averages are shown. $C$, Averaged $E_{s y n}^{r e v}$ curves calculated only for neurons spiking during SWRs show cell-type specific appearance. $E_{s y n}^{r e v}$ in the majority of neuron types reaches its maximum before or around the peak of the sharp waves, followed by the sharp drop toward more negative values. However, $E_{s y n}^{\text {rev }}$ for PV + BCs and OLM cells, is more symmetric relative to the sharp wave peak unlike $E_{s y n}^{r e v}$ for other cell types. Curves are the averages of $E_{s y n}^{r e v}$ obtained in individual cells. $\boldsymbol{D}$, Relationship between the peak of $E_{s y n}^{r e v}$ and the number of spikes during SWRs in different cell classes indicates that more spikes are emitted by those neuron types, in which the peak of $E_{s y n}^{r e v}$ approaches closer the reversal potential of the synaptic excitation. Error bars indicate SEM. $E, F$, Asymmetry in $E_{s y n}^{r e v}$ shows significant correlation with the asymmetry in spike distribution histograms for interneurons $(\boldsymbol{F})$, but not for pyramidal cells $(\boldsymbol{E})$.

distinct neuron types during SWRs could be also affected by single-cell properties, including the firing thresholds or passive and active membrane features, or other factors.

\section{Distinct types of interneurons receive different synaptic inputs during SWRs}

The analysis of the temporal structure of synaptic inputs in relation to the SWR peak uncovered that the magnitudes of excitatory and inhibitory synaptic charge as well as their ratios were very different in the three types of interneurons innervating the perisomatic region of pyramidal cells. This finding corresponds to the anatomical observations that $\mathrm{PV}+$ interneurons receive

three times more excitatory, but the same number of inhibitory synapses, than CB1+BCs (Gulyas et al., 1999; Matyas et al., 2004). These data and the observation that fast spiking (i.e., $\mathrm{PV}+$ ) interneurons could be excited more easily by intrahippocampal afferents than regular spiking (i.e., $\mathrm{CB1}+$ ) basket cells (Glickfeld and Scanziani, 2006) are in line with our results showing that $\mathrm{PV}+\mathrm{BCs}$ received larger synaptic excitation, but similar synaptic inhibition during SWRs than $\mathrm{CB} 1+\mathrm{BCs}$. The former cells also discharged more spikes than the latter interneurons. Neither previous anatomical works nor electrophysiological studies have compared the input properties of $\mathrm{PV}+\mathrm{BCs}$ and AACs to each other in the hippocampus. Our present data propose that either their dendritic arborization pattern or the synaptic features of their afferents should be significantly different. First, much larger synaptic inhibition was recorded during SWRs in AACs than in $\mathrm{PV}+\mathrm{BCs}$, implying that AACs receive more numerous and/or stronger inhibitory synaptic inputs from $\mathrm{PV}+\mathrm{BCs}$ than $\mathrm{PV}+\mathrm{BCs}$ from each other, if the main source of perisomatic inhibition during SWRs is originated from PV+BCs. Second, we observed a change in the temporal structure of synaptic inputs received by AACs during SWRs relative to the sharp wave peak, which was not detected in $\mathrm{PV}+$ or $\mathrm{CB} 1+\mathrm{BCs}$. This change in synaptic charge recorded in AACs during SWRs may reflect an enhanced synaptic inhibition after the sharp wave peak relative to the IPSG before the peak (Figs. $7 \mathrm{H}, 8 \mathrm{~B}, \mathrm{C}$ ), and/or a reduced synaptic excitation after the sharp wave peak relative to the EPSG before the peak (Fig. 7G). The latter scenario is unlikely, because no evidence implies so far that PV+BCs and AACs receive excitatory inputs from distinct sets of CA3 pyramidal cells, which could explain our findings. In any case, AACs should receive different inputs than basket cells and/or the short-term dynamics of these afferents could be dissimilar. Indeed, data from other cortical regions argue for the difference in synaptic inputs. For instance, AACs were found to be excited differently than basket cells by sensory input in the neocortex (Zhu et al., 2004) or upon noxious stimulus in the basolateral amygdala (Bienvenu et al., 2012), suggesting distinct excitatory recruitment of AACs in cortical networks.

The number of excitatory input onto GABAergic projection neurons (resembling OR cells in this study) was found to be comparable to PV+ interneurons (Gulyas et al., 1999; Takacs et al., 2008). Whereas both of these cell types significantly increase their firing rate to a similar extent during SWRs in vivo (Klausberger et al., 2003; Jinno et al., 2007; Lapray et al., 2012; Varga et al., 2012), OR cells spiked less and received smaller EPSG than 
$\mathrm{PV}+\mathrm{BCs}$ during SWRs in hippocampal slices. This contradiction might imply that $\mathrm{PV}+\mathrm{BCs}$ may receive a larger number of excitatory inputs from surrounding pyramidal cells, thus, are entrained by the activity of local neuronal networks (which is more intact in slices), whereas GABAergic projection cells could monitor more global changes in hippocampal activity.

\section{Perisomatic inhibition is one of the main sources of the field signal of SWRs in the stratum pyramidale}

Our results propose that in CA3 the synaptic output of GABAergic cells substantially contributes to the deflection in LFP, which might be reflected as an active source during SWRs (Fig. $1 D$ ). In accord, blocking of $\mathrm{GABA}_{\mathrm{A}}$ receptor-mediated synaptic transmission eliminates SWRs in CA3 in vitro (Maier et al., 2003; Ellender et al., 2010). The large current source restricted to the stratum pyramidale suggests that perisomatic region-targeting interneurons are the most likely candidates playing key roles in SWR generation in vitro. Because AACs and $\mathrm{CB} 1+\mathrm{BCs}$ are much less active interneurons during SWRs than $\mathrm{PV}+\mathrm{BC}$, we propose that the recruitment of these latter perisomatic region-targeting interneurons by local pyramidal cell ensembles is the crucial step in SWR generation.

In CA3, both gamma oscillations and SWRs are generated during different behavioral states in freely moving animals (Chrobak et al., 2000). Strikingly, these mutually exclusive oscillations, accompanying distinct neuronal information processing modes (Buzsáki, 2006), might be produced by the same neuronal circuit composed of recurrently connected pyramidal cells and $\mathrm{PV}+\mathrm{BCs}$ in the CA3 region of the hippocampus (Gulyas et al., 2010). An exciting question for future research is related to the switch between information processing modes in SWR-related and gamma oscillation-related network operations within the same rhythm-generating network.

\section{References}

Behrens CJ, van den Boom LP, de Hoz L, Friedman A, Heinemann U (2005) Induction of sharp wave-ripple complexes in vitro and reorganization of hippocampal networks. Nat Neurosci 8:1560-1567. CrossRef Medline

Bienvenu TC, Busti D, Magill PJ, Ferraguti F, Capogna M (2012) Cell-typespecific recruitment of amygdala interneurons to hippocampal theta rhythm and noxious stimuli in vivo. Neuron 74:1059-1074. CrossRef Medline

Borg-Graham LJ, Monier C, Frégnac Y (1998) Visual input evokes transient and strong shunting inhibition in visual cortical neurons. Nature 393: 369-373. CrossRef Medline

Buhl EH, Halasy K, Somogyi P (1994) Diverse sources of hippocampal unitary IPSPs and the number of synaptic release sites. Nature 368:823-828. CrossRef Medline

Buzsáki G (1986) Hippocampal sharp waves: their origin and significance. Brain Res 398:242-252. CrossRef Medline

Buzsáki G (1989) Two-stage model of memory trace formation: a role for "noisy" brain states. Neuroscience 31:551-570. CrossRef Medline

Buzsáki G (2006) Rhythms of the brain. New York: Oxford UP.

Chrobak JJ, Buzsáki G (1996) High-frequency oscillations in the output networks of the hippocampal-entorhinal axis of the freely behaving rat. J Neurosci 16:3056-3066. Medline

Chrobak JJ, Lörincz A, Buzsáki G (2000) Physiological patterns in the hippocampo-entorhinal cortex system. Hippocampus 10:457-465. CrossRef Medline

Csicsvari J, Hirase H, Mamiya A, Buzsáki G (2000) Ensemble patterns of hippocampal CA3-CA1 neurons during sharp wave-associated population events. Neuron 28:585-594. CrossRef Medline

de la Prida LM, Huberfeld G, Cohen I, Miles R (2006) Threshold behavior in the initiation of hippocampal population bursts. Neuron 49:131-142. CrossRef Medline

de la Prida LM, Gal B (2004) Synaptic contributions to focal and widespread spatiotemporal dynamics in the isolated rat subiculum in vitro. J Neurosci 24:5525-5536. CrossRef Medline
Dragoi G, Carpi D, Recce M, Csicsvari J, Buzsáki G (1999) Interactions between hippocampus and medial septum during sharp waves and theta oscillation in the behaving rat. J Neurosci 19:6191-6199. Medline

Ellender TJ, Nissen W, Colgin LL, Mann EO, Paulsen O (2010) Priming of hippocampal population bursts by individual perisomatic-targeting interneurons. J Neurosci 30:5979-5991. CrossRef Medline

Fisher NI (1993) Statistical analysis of circular data. Cambridge, UK: Cambridge UP.

Freund TF, Buzsáki G (1996) Interneurons of the hippocampus. Hippocampus 6:347-470. Medline

Fuentealba P, Begum R, Capogna M, Jinno S, Márton LF, Csicsvari J, Thomson A, Somogyi P, Klausberger T (2008) Ivy cells: a population of nitric-oxideproducing, slow-spiking GABAergic neurons and their involvement in hippocampal network activity. Neuron 57:917-929. CrossRef Medline

Girardeau G, Benchenane K, Wiener SI, Buzsáki G, Zugaro MB (2009) Selective suppression of hippocampal ripples impairs spatial memory. Nat Neurosci 12:1222-1223. CrossRef Medline

Glickfeld LL, Scanziani M (2006) Distinct timing in the activity of cannabinoid-sensitive and cannabinoid-insensitive basket cells. Nat Neurosci 9:807-815. CrossRef Medline

Gulyas AI, Megías M, Emri Z, Freund TF (1999) Total number and ratio of excitatory and inhibitory synapses converging onto single interneurons of different types in the CA1 area of the rat hippocampus. J Neurosci 19: 10082-10097. Medline

Gulyás AI, Hájos N, Katona I, Freund TF (2003) Interneurons are the local targets of hippocampal inhibitory cells which project to the medial septum. Eur J Neurosci 17:1861-1872. CrossRef Medline

Gulyás AI, Szabó GG, Ulbert I, Holderith N, Monyer H, Erdélyi F, Szabó G, Freund TF, Hajás N (2010) Parvalbumin-containing fast-spiking basket cells generate the field potential oscillations induced by cholinergic receptor activation in the hippocampus. J Neurosci 30:15134-15145. CrossRef Medline

Hájos N, Ellender TJ, Zemankovics R, Mann EO, Exley R, Cragg SJ, Freund TF, Paulsen O (2009) Maintaining network activity in submerged hippocampal slices: importance of oxygen supply. Eur J Neurosci 29:319 327. CrossRef Medline

Jadhav SP, Kemere C, German PW, Frank LM (2012) Awake hippocampal sharp-wave ripples support spatial memory. Science 336:1454-1458. CrossRef Medline

Jinno S, Klausberger T, Marton LF, Dalezios Y, Roberts JD, Fuentealba P, Bushong EA, Henze D, Buzsáki G, Somogyi P (2007) Neuronal diversity in GABAergic long-range projections from the hippocampus. J Neurosci 27:8790-8804. CrossRef Medline

Klausberger T, Somogyi P (2008) Neuronal diversity and temporal dynamics: the unity of hippocampal circuit operations. Science 321:53-57. CrossRef Medline

Klausberger T, Magill PJ, Márton LF, Roberts JD, Cobden PM, Buzsáki G, Somogyi P (2003) Brain-state- and cell-type-specific firing of hippocampal interneurons in vivo. Nature 421:844-848. CrossRef Medline

Kubota D, Colgin LL, Casale M, Brucher FA, Lynch G (2003) Endogenous waves in hippocampal slices. J Neurophysiol 89:81-89. CrossRef Medline

Lapray D, Lasztoczi B, Lagler M, Viney TJ, Katona L, Valenti O, Hartwich K, Borhegyi Z, Somogyi P, Klausberger T (2012) Behavior-dependent specialization of identified hippocampal interneurons. Nat Neurosci 15: 1265-1271. CrossRef Medline

Lasztóczi B, Tukker JJ, Somogyi P, Klausberger T (2011) Terminal field and firing selectivity of cholecystokinin-expressing interneurons in the hippocampal CA3 area. J Neurosci 31:18073-18093. CrossRef Medline

Le Van Quyen M, Bragin A, Staba R, Crépon B, Wilson CL, Engel J Jr (2008) Cell type-specific firing during ripple oscillations in the hippocampal formation of humans. J Neurosci 28:6104-6110. CrossRef Medline

Logothetis NK, Eschenko O, Murayama Y, Augath M, Steudel T, Evrard HC, Besserve M, Oeltermann A (2012) Hippocampal-cortical interaction during periods of subcortical silence. Nature 491:547-553. CrossRef Medline

López-Bendito G, Sturgess K, Erdélyi F, Szabó G, Molnár Z, Paulsen O (2004) Preferential origin and layer destination of GAD65-GFP cortical interneurons. Cereb Cortex 14:1122-1133. CrossRef Medline

Maier N, Nimmrich V, Draguhn A (2003) Cellular and network mechanisms underlying spontaneous sharp wave-ripple complexes in mouse hippocampal slices. J Physiol 550:873-887. CrossRef Medline

Mátyás F, Freund TF, Gulyás AI (2004) Convergence of excitatory and in- 
hibitory inputs onto CCK-containing basket cells in the CA1 area of the rat hippocampus. Eur J Neurosci 19:1243-1256. CrossRef Medline

Meyer AH, Katona I, Blatow M, Rozov A, Monyer H (2002) In vivo labeling of parvalbumin-positive interneurons and analysis of electrical coupling in identified neurons. J Neurosci 22:7055-7064. Medline

Nakashiba T, Buhl DL, McHugh TJ, Tonegawa S (2009) Hippocampal CA3 output is crucial for ripple-associated reactivation and consolidation of memory. Neuron 62:781-787. CrossRef Medline

Oren I, Mann EO, Paulsen O, Hájos N (2006) Synaptic currents in anatomically identified CA3 neurons during hippocampal gamma oscillations in vitro. J Neurosci 26:9923-9934. CrossRef Medline

Somogyi P, Klausberger T (2005) Defined types of cortical interneurone structure space and spike timing in the hippocampus. J Physiol 562:9-26. CrossRef Medline

Sullivan D, Csicsvari J, Mizuseki K, Montgomery S, Diba K, Buzsáki G (2011) Relationships between hippocampal sharp waves, ripples, and fast gamma oscillation: influence of dentate and entorhinal cortical activity. J Neurosci 31:8605-8616. CrossRef Medline
Takács VT, Freund TF, Gulyás AI (2008) Types and synaptic connections of hippocampal inhibitory neurons reciprocally connected with the medial septum. Eur J Neurosci 28:148-164. CrossRef Medline

Ulbert I, Halgren E, Heit G, Karmos G (2001) Multi microelectroderecording system for human intracortical applications. J Neurosci Methods 106:69-79. CrossRef Medline

Varga C, Golshani P, Soltesz I (2012) Frequency-invariant temporal ordering of interneuronal discharges during hippocampal oscillations in awake mice. Proc Natl Acad Sci U S A 109:E2726-2734. CrossRef Medline

Wu C, Asl MN, Gillis J, Skinner FK, Zhang L (2005) An in vitro model of hippocampal sharp waves: regional initiation and intracellular correlates. J Neurophysiol 94:741-753. CrossRef Medline

Zar JH (1999) Biostatistical analysis. Upper Saddle River, NJ: Prentice Hall.

Zhu Y, Stornetta RL, Zhu JJ (2004) Chandelier cells control excessive cortical excitation: characteristics of whisker-evoked synaptic responses of layer $2 / 3$ nonpyramidal and pyramidal neurons. J Neurosci 24:51015108. CrossRef Medline 